\title{
Phylogeny of Crataegus (Rosaceae) based on 257 nuclear loci and chloroplast genomes: evaluating the impact of hybridization
}

\author{
Aaron Liston ${ }^{\text {Corresp. Equal first author, } 1 \text {, Kevin A Weitemier }}{ }^{1,2}{ }^{2}$ Lucas Letelier $^{1}$, János Podani ${ }^{3}$, Yu Zong ${ }^{1,4}$, Lang Liu ${ }^{5}$, \\ Timothy A Dickinson Equal first author, 6, 7

Background. Hawthorn species (Crataegus L.; Rosaceae tribe Maleae) form a well-defined clade comprising five subgeneric groups readily distinguished using either molecular or morphological data. While multiple subsidiary groups (taxonomic sections, series) are recognized within some subgenera, the number of and relationships among species in these groups are subject to disagreement. Gametophytic apomixis and polyploidy are prevalent in the genus, and disagreement concerns whether and how apomictic genotypes should be recognized taxonomically. Recent studies suggest that many polyploids arise from hybridization between members of different infrageneric groups.

Methods. We used target capture and high throughput sequencing to obtain nucleotide sequences for 257 nuclear loci and nearly complete chloroplast genomes from a sample of hawthorns representing all five currently recognized subgenera. Our sample is structured to include two examples of intersubgeneric hybrids and their putative diploid and tetraploid parents. We queried the alignment of nuclear loci directly for evidence of hybridization, and compared individual gene trees with each other, and with both the maximum likelihood plastome tree and the nuclear concatenated and multilocus coalescent-based trees. Tree comparisons provided a promising, if challenging (because of the number of comparisons involved) method for visualizing variation in tree topology. We found it useful to deploy comparisons based not only on tree-tree distances but also on a metric of tree-tree concordance that uses extrinsic information about the relatedness of the terminals in comparing tree topologies.

Results. We obtained well-supported phylogenies from plastome sequences and from a minimum of 244 low copy-number nuclear loci. These are consistent with a previous morphology-based subgeneric classification of the genus. Despite the high heterogeneity of individual gene trees, we corroborate earlier evidence for the importance of hybridization in the evolution of Crataegus. Hybridization between subgenus Americanae and subgenus Sanguineae was documented for the origin of Sanguineae tetraploids, but not for a tetraploid Americanae species. This is also the first application of target capture probes designed with apple genome sequence. We successfully assembled $95 \%$ of 257 loci in Crataegus, indicating their potential utility across the genera of the apple tribe. 


\section{Phylogeny of Crataegus (Rosaceae) based on 257}

2 nuclear loci and chloroplast genomes: evaluating the

3 impact of hybridization

4

5

6
Aaron Liston ${ }^{1}$ Orcid iD 0000-0002-3020-6400, Kevin A. Weitemier ${ }^{1,2}$, Lucas Letelier ${ }^{1}$, János Podani $^{3}$ Orcid iD 0000-0002-1452-1486, Yu Zong ${ }^{1,4}$ Orcid iD 0000-0001-6432-8089, Lang Liu ${ }^{5}$, Timothy A. Dickinson ${ }^{6,7}$ Orcid iD 0000-0003-1366-145X

${ }^{1}$ Department of Botany and Plant Pathology, Oregon State University, Corvallis, Oregon, USA USA

${ }^{2}$ Department of Fisheries and Wildlife, Oregon State University, Corvallis, Oregon, USA

${ }^{3}$ Department of Plant Systematics, Ecology and Theoretical Biology, Eötvös University, Budapest, Hungary

${ }^{4}$ College of Chemistry \& Life Sciences, Zhejiang Normal University, Jinhua, Zhejiang, China

${ }^{5}$ Cell \& Systems Biology, University of Toronto, Toronto, Ontario, Canada

${ }^{6}$ Natural History, Royal Ontario Museum, Toronto, Ontario, Canada

${ }^{7}$ Ecology \& Evolutionary Biology, University of Toronto, Toronto, Ontario, Canada

Equal First Authors: Aaron Liston and Timothy A. Dickinson

Corresponding Author:

Aaron Liston ${ }^{1}$

4575 SW Research Way, Corvallis, OR, 97333, USA

Email address: aaron.liston@oregonstate.edu 
30

31

32

33

34

35

36

37

38

39

40

41

42

43

44

45

46

47

48

49

50

51

52

53

54

55

56

57

58

59

60

61

62

63

64

65

66

67

68

69

70

71

72

\section{Abstract}

Background. Hawthorn species (Crataegus L.; Rosaceae tribe Maleae) form a well-defined clade comprising five subgeneric groups readily distinguished using either molecular or morphological data. While multiple subsidiary groups (taxonomic sections, series) are recognized within some subgenera, the number of and relationships among species in these groups are subject to disagreement. Gametophytic apomixis and polyploidy are prevalent in the genus, and disagreement concerns whether and how apomictic genotypes should be recognized taxonomically. Recent studies suggest that many polyploids arise from hybridization between members of different infrageneric groups.

Methods. We used target capture and high throughput sequencing to obtain nucleotide sequences for 257 nuclear loci and nearly complete chloroplast genomes from a sample of hawthorns representing all five currently recognized subgenera. Our sample is structured to include two examples of intersubgeneric hybrids and their putative diploid and tetraploid parents. We queried the alignment of nuclear loci directly for evidence of hybridization, and compared individual gene trees with each other, and with both the maximum likelihood plastome tree and the nuclear concatenated and multilocus coalescent-based trees. Tree comparisons provided a promising, if challenging (because of the number of comparisons involved) method for visualizing variation in tree topology. We found it useful to deploy comparisons based not only on tree-tree distances but also on a metric of tree-tree concordance that uses extrinsic information about the relatedness of the terminals in comparing tree topologies.

Results. We obtained well-supported phylogenies from plastome sequences and from a minimum of 244 low copy-number nuclear loci. These are consistent with a previous morphology-based subgeneric classification of the genus. Despite the high heterogeneity of individual gene trees, we corroborate earlier evidence for the importance of hybridization in the evolution of Crataegus. Hybridization between subgenus Americanae and subgenus Sanguineae was documented for the origin of Sanguineae tetraploids, but not for a tetraploid Americanae species. This is also the first application of target capture probes designed with apple genome sequence. We successfully assembled $95 \%$ of 257 loci in Crataegus, indicating their potential utility across the genera of the apple tribe.

\section{Introduction}

The relative importance of hybridization in the evolution of Crataegus L. (and in some other Rosaceae) has been contentious in the past, and is reviewed elsewhere (Dickinson 2018); it suffices for now to note that just within subtribe Malinae (fleshy fruits derived from hypanthial, or inferior, ovaries; Rosaceae subfamily Amygdaloideae) there are molecular data to document hybridization in several large genera (Burgess et al. 2015; Cushman et al. 2017; Hamston et al. 2018; Li et al. 2014; Li et al. 2017; Liu et al. 2020; Németh et al. 2020), including Crataegus. This genus of approximately 200 or more species (Phipps 2015) is found in a small clade of five genera and ca. 270 species in total that is sister group to the remaining 24 genera and ca. 530 species of Malinae (Mabberley 2008; Campbell et al. 2015; Tropicos.org 2021). Together with Hesperomeles Lindl. (Li et al. 2012; Liu et al. 2020), Crataegus diverged from unarmed, berryfruited Amelanchier, Malacomeles, and Peraphyllum by the acquisition of thorns and polypyrenous drupes whose pyrenes enclose a single seed (Campbell et al. 2007; Lo \& 
Donoghue 2012; Potter et al. 2007; Xiang et al. 2017; Zhang et al. 2017). Crataegus encompasses considerable variation in its thorns, leaves, flowers, and fruits, such that there is a well-developed infrageneric classification (Table 1; Loudon 1838; Palmer 1925; Phipps 2015; Schneider 1906; Ufimov \& Dickinson 2020) that is supported by DNA sequence data (Fig. 1; Lo \& Donoghue 2012; Lo et al. 2009a; Zarrei et al. 2015; Ufimov et al. 2021). Nevertheless, comparisons of microsatellites, and of nuclear and chloroplast loci (Lo et al. 2009b; Lo et al. 2010), and ribosomal DNA (ITS2) copy number variation correlated with differences in ploidy level (Zarrei et al. 2014), strongly suggest that hybridization between infrageneric groups (subgenera, sections, series) has played an important role in the diversification of Crataegus. Prior to these data becoming available, however, with one exception (Phipps 1988) hybridization was not seen to be a factor in Crataegus diversification (Haines 2011; Phipps 2005), and several new species were described in North America during the period 1980-2007 with their possible hybrid origin being either ignored or explicitly rejected. Subsequently, however, taxonomic and floristic works on Crataegus have reversed this trend (Kurtto et al. 2013; Lance 2014; Phipps 2013; Phipps 2015). Because both ploidy level variation and hybridization are usually associated with uniparental reproduction by means of gametophytic apomixis the cumulative consequences, in terms of taxonomic complexity, have been considerable.

For an orthologous nucleotide site, its entire geneaological history can accurately be represented as a single evolutionary tree (Ralph et al. 2020). However, once multiple nucleotides are examined, the processes of mutation and recombination will create different bifurcating histories among nucleotides in a genome. Once population divergence and speciation occur, incomplete lineage sorting (ILS) further contributes to discordant phylogenetic trees across the genome (Degnan and Rosenberg 2009). Incomplete lineage sorting can be modeled and accounted for in methods that aim to reconstruct a species tree from an assemblage of individual gene trees (Zhang et al. 2018), and its potential impact on phylogenetic reconstruction can be quantified with gene and nucleotide site concordance measures (Minh et al. 2020a). These methods require a large number of loci. Fortunately, current methods allow for the sequencing and efficient analysis of hundreds to thousands of nuclear loci (Weitemier et al. 2014; Johnson et al. 2016), and are applied here to estimate phylogenetic relationships among species of the genus Crataegus.

However, organismal diversification is not a strictly bifurcating process, due to the widespread occurrence of interspecific hybridization. Like recombination and ILS, hybridization will also result in conflict among gene trees, as each sequence obtained from an individual of a hybrid species will originate from only one of its progenitors. Thus, different gene trees will trace different ancestries, resulting in conflict. Discerning whether conflict results from ILS or reticulation is particularly difficult, but recent progress with methods based on nucleotide site pattern probabilities have made this tractable (Blischak et al. 2018), and this approach is applied here. Conflicts among nucleotide site patterns are also analyzed with a splits network (Huson \& Bryant 2005) to provide a visualization of reticulate events.

Alternatively, all alleles at a locus can be obtained for a hybrid individual (Rothfels, 2021), but the technical and analytical demands of this approach can be prohibitive, and may minimally impact phylogenetic reconstruction (Kates et al. 2018). Furthermore, the presence of 
118 multiple sequences per individual requires multi-labelled trees, which also present analytical

119

120

121

122

123

124

125

126

127

128

129

130

131

132

133

134

135

136

137

138

139

140

141

142

143

144

145

146

147

148

149

150

151

152

153

154

155

156

157

158

159

160

161

162

163

challenges (Rothfels, 2021). For these reasons, we do not incorporate these methods.

In addition to using sequence evolution methods for inferring phylogenetic relationships and hybridization, we investigate the information available in the topologies of a collection of 257 gene trees. We use two related methods to do so. First, we employ phenetic descriptors of tree topology, singly and combined, using the Euclidean distance to compare trees in an ordination space (principal coordinates analysis). Second, we employ two related measures designed for situations in which the tips of the trees are related according to some extrinsic factor such as taxonomic group: the Related tree distance (RT), and a concordance measure. Both measures depend on collapsing a reference tree so as to represent only the relationships between extrinsic groups. In this way each of these measures (RT, rtCF) depicts the extent to which a given sample tree reflects the relationships seen in the reference tree between the extrinsic groups. In this way we seek to interrogate the structure of our gene trees for evidence of hybridization or other processes that would confound the ability of an individual gene tree to document relationships seen in the reference tree that we believe to have priority, based on nonmolecular or other information. We use these tree descriptors to demonstrate their utility for analyses of the topological congruence among trees.

\section{Materials \& Methods}

Taxon sampling - The focus of our work to date is Crataegus subg. Sanguineae, and the black-fruited hawthorns that are its North American representatives (Coughlan et al. 2017; Coughlan et al. 2014; Dickinson et al. 1996; Dickinson et al. 2008; Dickinson \& Love 1997; Evans \& Dickinson 1996; Lo et al. 2009b; Lo et al. 2013; Ufimov \& Dickinson 2020; Zarrei et al. 2014). We supplement these earlier results, where they were based on a limited number of loci, by obtaining total genomic DNA from leaf tissue dried on silica gel for 24 field- or gardencollected Crataegus individuals for which ploidy level had been determined previously by flow cytometry (Table 1; cf. Talent \& Dickinson 2005). Our sample encompasses all five Crataegus subgenera recognized at present, each one represented by one or more species shown to be diploid, for a total of 14 diploid Crataegus accessions (Table 1). These diploid accessions also include representatives of all the taxonomic sections of $C$. subg. Americanae and $C$. subg. Sanguineae (Table 1). To this sample we have added four accessions representing tetraploid species in $C$. subg. Americanae, C. chrysocarpa and C. macracantha (Table 1). We have also added six accessions representing two primarily tetraploid species in $C$. subg. Sanguineae, $C$. douglasii and C. rivularis (Table 1). One of the $C$. douglasii accessions is a triploid. Triploids are rare in C. douglasii (Talent \& Dickinson 2005; Dickinson et al. in prep.-b). References below to tetraploids include this triploid C. douglasii individual (s16, Table 1). In this way our sample comprises diploid and tetraploid representatives of each of subg. Sanguineae sections Douglasianae and Salignae (Table 1). The Sanguineae tetraploids have been shown to be allopolyploids that combine Americanae and Sanguineae genomes (Table 2; Zarrei et al. 2014). The Americanae tetraploids were chosen because they are the only widespread, common species of this subgenus with ranges that overlap at least in part with those of $C$. sections Douglasianae and Salignae (Dickinson et al. in prep.-a; Dickinson et al. in prep.-b; Phipps 2015) and so are likely representative of the Americanae parent(s) of the intersubgeneric hyrids. The corresponding representatives of the maternal Sanguineae parents are the two diploid accessions

Peer] reviewing PDF | (2020:12:56540:2:0:NEW 30 Sep 2021) 
164 of C. suksdorfii sensu lato and of C. saligna Greene (Table 1; cf. Zarrei et al. 2014). North

165 American hawthorns vary discontinuously in stamen number per flower in a manner correlated

166 with ploidy level such that the derived number (5-10) has only been found in polyploids, while

167 diploids have been shown so far to have exclusively 15-20 (or more) stamens per flower (Table

168 2). With a single exception known to date Eurasian Crataegus species have 15-20 stamens per

169 flower regardless of ploidy level (Christensen 1992).

170

171

172

DNA extraction, sample preparation, and sequencing - DNA was extracted from dried tissue using the FastDNA Spin Kit from MPBiomedicals (Santa Ana, CA, USA) following manufacturer's protocols, modified by the addition of $40 \mu \mathrm{L} 1 \%$ polyvinylpyrrolidone and $10 \mu \mathrm{L}$ $\beta$-mercaptoethanol to the lysis solution prior to grinding. Aliquots of isolated DNA were sheared with a BioRuptor ${ }^{\circledR}$ Pico sonicator (Diagenode Inc., Denville, NJ, USA) for 30 cycles of $30 \mathrm{~s}$ on, $30 \mathrm{~s}$ off. Libraries for sequencing were prepared using the NEBNext ${ }^{\circledR}$ Ultra $^{\mathrm{TM}}$ DNA Library Prep Kit for Illumina ${ }^{\circledR}$ (New England Biolabs, Ipswich, MA, USA). Samples were dual indexed using both the $i 5$ and $i 7$ primers from the NEBNext ${ }^{\circledR}$ Multiplex Oligos for Illumina ${ }^{\circledR}$ (Dual Index Primers Set 1).

180

A set of probes targeting 257 conserved, putatively orthologous nuclear loci

Bioinformatics - Nucleotide sequences were quality trimmed (Q15 on left, Q10 on right) and Illumina adapters were removed using cutadapt (Martin 2011). Duplicated reads were reduced by calculating coverage of unique reads in assembly and reducing duplicated reads to represent the same coverage. Cleaned reads were assembled with HybPiper (Johnson et al. 2016) using default parameters. The coding regions (CDS) of the 257 apple genes (Velasco et al. 2010) were used as read mapping targets, with ambiguous bases in the apple sequence $(0.2 \%$ the total bases $)$ replaced with Ns. The CDS sequences were assembled for all individuals at each locus. Multiple sequence files for all individuals and diploids only were aligned with MAFFT v7.402 (Katoh \& Standley 2013). We used the MAFFT default alignment settings and the "auto" option which selects an appropriate algorithm according to data size (Supplemental Tables S2, S3). All alignments were visually inspected, and those with $>20 \mathrm{bp}$ of non-homologous sequence in two or more samples were flagged as poor-quality alignments. If misaligned regions were found at the end or ends of the alignments, they were deleted (but only if that left $600 \mathrm{bp}$ or more). In addition, alignments with two or more sequences identified by HybPiper as potential paralogs were noted. 
209 Phylogeny inference from nuclear data - Phylogenetic relationships were estimated with IQ-

210 TREE v. 1.7-beta7 (Nguyen et al. 2015). First a concatenation of all included nuclear gene

211 alignments was used to reconstruct a maximum-likelihood (ML) species tree using an edge-

212 linked proportional partition model and 1000 rapid bootstrap replicates. Next, an ML gene tree

213 was reconstructed for each locus. Best fit substitution models were obtained with the

214 ModelFinder option (Kalyaanamoorthy et al. 2017), while branch support was obtained using the

215 ultrafast bootstrap (Hoang et al. 2018) and the SH-aLR test (Guindon et al. 2010; Minh et al.

216 2020b). To protect against overestimating branch support because of severe model violations we

217 used the option to optimize the bootstrap trees by nearest-neighbor interchanges in the bootstrap

218 alignments (Minh et al. 2020b). Finally, the concordance and discordance factors were calculated

219 by IQ-TREE for each branch in the 14- and 24-accession trees (Lanfear 2018; Minh et al.

220 2020a). The gene concordance factor ( $\mathrm{gCF}$ ) is defined as the percentage of decisive gene trees

221

222

223

224

225

226

227

228

229

230

231

232

233

234

235

236

237

238

239

240

241

242

243

244

245

246

247

248

249

250

251

252

253

254 containing that branch. The site concordance factor ( $\mathrm{sCF}$ ) is defined as the percentage of decisive sites supporting a branch. Discordance factors quantify the amount of disagreement among loci and sites, and are defined as the percentages of genes (gDF) and sites (sDF) supporting alternative resolutions (nearest-neighbor interchanges) of a given branch (Minh et al. 2020a). The gene discordance factors are the percentages of decisive trees supporting a second, alternative resolution of the four clades around this branch $\left(\mathrm{gDF}_{1}\right)$, and the percentages of decisive trees supporting a third, alternative resolution of the four clades around this branch $\left(\mathrm{gDF}_{2}\right)$. Analogously, the site discordance factors answer the question, "which of the three possible quartets around a given branch" does a site support (Lanfear 2018)? These are calculated using the number of decisive sites ( $\mathrm{sN}$ ) averaged over many possible quartets partitioned between the one supporting the tree obtained (sCF) and those supporting the next two best resolutions $\left(\mathrm{sDF}_{1}, \mathrm{sDF}_{2}\right)$. We also carried out a test of $\mathrm{H}_{0}$ : incomplete lineage sorting (ILS) is responsible for approximately equal numbers of genes supporting alternative topologies (Lanfear 2018) using the data and graphics analysis environment R (R Core Team 2016). In fact, except as noted, R packages and functions were used for all of the data manipulations and analyses described below.

The multi-species coalescent model of ASTRAL-III v. 5.6.3 (Zhang et al. 2018) was also used to estimate phylogenetic relationships for the diploid species and diploid plus polyploid species using 244 nuclear loci found in all samples, and 245 nuclear loci found in all diploid samples. Sequence obtained from the Malus $\times$ domestica 'Golden Delicious' genome (Velasco et al. 2010) was specified as the outgroup for the above analyses.

Phylogeny inference from plastome data - Plastome sequences were obtained from the unenriched fraction of target capture libraries (Weitemier et al. 2014). To assemble the plastomes, SPAdes v. 3.6.0 (Bankevich et al. 2012) was used for de novo assembly of the cleaned reads from each sample. Resulting scaffolds were aligned to the Malus $\times$ domestica 'Golden Delicious' plastome sequence (Velasco et al., 2010) with BLAT (Kent 2002). One copy of the inverted repeat was removed from the apple sequence before alignment. The multiple alignment files were imported into Geneious v. 6.1 .8 (Kearse et al. 2012) and manually refined. Consensus sequences were output and aligned with MAFFT v7.312. Gblocks v 0.91b (Talavera \& Castresana 2007) was used to remove ambigously aligned sequence (block size of 10, maximum of 8 non-conserved positions or $>50 \%$ gaps). Maximum likelihood estimation for the plastome phylogeny was conducted with IQ-TREE (Nguyen et al. 2015) as described above for

Peer) reviewing PDF | (2020:12:56540:2:0:NEW 30 Sep 2021) 
255 the individual nuclear loci. The plastome was treated as a single locus for phylogenetic analysis,

256

257

258

259

260

261

262

263

264

265

266

267

268

269

270

271

272

273

274

275

276

277

278

279

280

281

282

283

284

285

286

287

288

289

290

291

292

293

294

295

296

297

298

299

300 in accord with Doyle (2021).

Linkage group localization - We used the BLAST functionality of the Genome Database for Rosaceae (Jung et al. 2019) to localize to their apple chromosome the apple loci whose Crataegus counterparts we recovered, using both the GDDH13 v1.1 (Daccord et al. 2017) and the HFTH1 Genome v1.0.a1 (Zhang et al. 2019) chromosome databases.

Phylogenetic invariants - We also used our concatenated nuclear sequence alignment $(529,827$ sites) to test hypotheses of $C$. subg. Sanguineae $\times C$. subg. Americanae hybridization for $C$. douglasii and $C$. rivularis using coalescent-based phylogenetic invariants and the software package HyDe (Blischak et al. 2018). In this way we tested $\mathrm{H}_{0}$ : the admixture statistic $(\gamma)=0$ (i.e. no admixture). After converting the sequence data from FASTA to PHYLIP format with Fasta2Phylip.pl (Deng 2007) or the dat2phylip function in the phylotools package (Zhang 2017), for each species a selection of 13 accessions (four outgroups, three supposed hybrids, two diploid subg. Sanguineae parents, and four subg. Americanae tetraploid parents; Table 1) was tested at the level of populations and individuals, the latter with and without bootstrapping. Distributions of the admixture statistic $(\gamma)$ were plotted as suggested by Kabacoff (2017). To provide context for these results we also used HyDe to test for any signal of hybridization in the sequence data for tetraploid C. macracantha using the single accession of diploid $C$.

calpodendron as one parent ( $\mathrm{P} 1)$, and either the remaining four Americanae diploids or the four Sanguineae diploids to represent the other parent (P2; Table 1). Crataegus calpodendron and $C$. macracantha are both placed in $C$. sect. Macracanthae, the smaller of the two sections in subg. Americanae that is distinguished in part by the excavations on the radial surfaces of the pyrenes, much as are taxa in subg. Sanguineae (Table 1; Phipps 2015). The four remaining Americanae diploids all belong to different series in the large section Coccineae (Table 1; Phipps 2015). A similar examination of tetraploid C. chrysocarpa was not carried out because there were no other species in our sample from $C$. ser. Rotundifolieae, let alone diploid ones, to serve as at least one plausible parent.

Splits network - The single locus sequence alignments in FASTA format of 244 low copy number nuclear loci $(529,827$ positions) available for the diploid plus polyploid species sample were concatenated into a single multilocus FASTA alignment with the perl script catfasta2phyml (Nylander 2020). This multilocus alignment was used to produce a network representation of the 24 hawthorn individuals (Table 1) using SplitsTree4 (Huson \& Bryant 2005) and the default NeighborNet parameters. The diagram was calculated from the uncorrected p-distances between the aligned sequences, with a fit $=97 \%$. Sequences from the apple (Malus $\times$ domestica Borkh.) genome (Velasco et al. 2010) were included as an outgroup. The diagram was colored using ColorBrewer 2.0 (Brewer 2013) and Adobe Illustrator 2020 (Adobe_Corp. 2019).

Gene tree comparisons - We evaluated the congruence of the gene trees we obtained, the extent to which they suggest that inferred $C$. subg. Sanguineae allotetraploids contain alleles indicative of their parentage, and the support these trees provide for the a priori classification of the sample based on earlier work (Fig. 2; Table 1). Using just the trees for our diploids-only sample, we tabulated taxonomically significant features of the reference trees (plastome and nuclear multilocus trees) and the single-locus trees, namely (a) sister-group relationships of the 
301 early-diverging subgenera, (b) the extent to which subgenera Americanae and Sanguineae

302 formed separate clades, and (c) the extent to which accessions belonging to the taxonomic

303 sections within the focal group for our study, $C$. subg. Sanguineae, also formed distinct clades.

304 We then examined how the topologies of the single-locus diploid-only trees best representing the

305 infrageneric classification were impacted, in parallel analyses, by the inclusion of allotetraploid

306 accessions. Except as noted, all analyses and manipulations of our trees were carried out in $\mathrm{R}$ ( $\mathrm{R}$

307 Core Team 2016) using the R package ape (Paradis et al. 2015).

308

309

310

311

312

313

314

315

316

317

318

319

320

321

322

323

324

325

326

327

328

329

330

331

332

333

334

335

336

337

338

339

340

341

342

343

344

345
The taxonomic structure in our sample provides two sets of categories to which our accessions belong, namely the subgenera and sections of the genus Crataegus (Table 1). Thus we also used the treeConcordance function in the R package treespace (Jombart et al. 2017) to measure the extent of the agreement between each of our single-locus trees and the hierarchical classification implied by the two sets of categories as seen in our plastome trees (calculated using the makeCollapsedTree function; Fig. 2). This was carried out separately for the sample of diploid accessions only, and for the diploid plus the allotetraploid accessions (Table 1). Ordering the trees according to their tree concordance values allowed us to compare highly concordant trees with ones that were only minimally so. The former were defined as exceeding the third quartile by more than $1.5 \times$ the interquartile range of the concordance values (documentation for the boxplot. stats function; R Core Team 2016), whereas the latter comprised the first quartile of concordance values. In order to distinguish the Kendall et al. tree concordance values from the gCF and $\mathrm{SCF}$ concordances calculated using IQ-TREE (above), we abbreviate these concordances as $\mathrm{rtCF}$, referring to the related sets of tips (categories) that make the measure possible.

We used the treespace function relatedTreeDist to calculate the Related Tree (RT) distances between trees (Kendall 2019; Kendall et al. 2018). This calculation involves comparing the collapsed forms of two trees with respect to whether the categories (here, subgenera or sections) in one or both remain monophyletic, so that the distance quantifies similarities and differences between the trees relative to phylogenetic relationships between the categories (Kendall 2019).

In addition, we used three descriptors of tree topology (Cluster Membership Divergence, CMD; Subtree Membership Divergence, SMD; and Partition Membership Divergence, PMD), singly and together (Podani 2000; Podani \& Dickinson 1984). Trees described in the Newick format (Felsenstein 2005) were converted to merge matrices (Hartigan 1967; Podani 1982) using program NTOS.EXE in the SYN-TAX 5.10 package (Podani 1993), having first replaced taxon labels with numbers, and branch lengths with arbitrary values. Merge matrices were concatenated and used as input to program DENDAT.EXE, in the SYN-TAX package, in order to calculate CMD, PMD, and SMD. Here, the number of OTUs in the tree is $N=15$ or $N=25$, so the number of pairwise comparisons is $w=N \times(N-1) / 2$, so that $w=105$ or 300 for each descriptor. We are comparing $k$ trees (including the plastome tree), so for each descriptor we obtain a data matrix with $w$ rows and $k$ columns and, for the three descriptors taken together, a matrix of $3 w$ rows and $k$ columns. These matrices were used as input to calculate Euclidean multivariate (MV) distances between all pairs of the $k$ trees using the R function dist. For more details, see Podani and Dickinson (1984) who explained the methodology with reference to a set 
346 of artificial trees, a set of dendrograms from a phenetic study of Crataegus, and a set of

347

348

349

350

351

352

353

354

355

356

357

358

359

360

361

362

363

364

365

366

367

368

369

370

371

372

373

374

375

376

377

378

379

380

381

382

383

384

385

386

387

388

389

390

391

cladograms from a published molecular phylogeny of mammals.

We calculated distances between our trees in order to display the variation they exhibit in the low-dimensional spaces of the first Principal Coordinates Analysis (PCoA) axes for which the proportion of variance accounted for by the axis exceeds that expected under the broken-stick model (Frontier 1976; Legendre \& Legendre 1998). Displayed in this way, we superimposed information about the rtCF values and distinguished between ones found to be highly concordant and others with the lowest rtCF values. PCoAs were calculated using the function pcoa in the R package ape (Paradis et al. 2015). We also clustered the trees based on the RT and MV distances between them by using the R function hclust. Scree plots of the PCoA eigenvalues were made from the output of the pcoa function.

\section{Results}

Target enrichment and plastome assembly - An average of 3.06 million reads were obtained per sample with an average $25.6 \%$ of reads on targeted nuclear loci. On average, 254.6 genes were recovered per sample, and 244 assemblies had sequence data for all samples, both diploid and tetraploid (Table 1). Assembled loci average 1262 bp and cover $81 \%$ of the target sequence. No ambiguous bases are present in the assembled sequences. The average total sequence length is $424.5 \mathrm{kbp}$ per sample. The median size of assembled plastomes was 130.7 $\mathrm{kbp}$. Four samples with plastome read coverage below $4.5 \times$ had incomplete assemblies, ranging from $112.6 \mathrm{kbp}$ to $123.0 \mathrm{kbp}$. The remaining samples with coverage above $4.5 \times$ had nearly complete assemblies.

Linkage group localization - The 257 loci recovered represent all 17 apple chromosomes, with six or more loci found on each chromosome, and 20 or more loci on each of chromosomes $6,11,15$, and 17 (Supplemental Table S1). Correspondingly fewer than the equidistribution localized to the remaining chromosomes. Six loci localized to unanchored scaffolds ("Chr00" Supplemental Table S1) in the Golden Delicious genome. Locus 99 found no hits on any of the scaffolds (Supplemental Table S1).

Plastome trees - Plastome trees were generally well-supported in terms of bootstrap values as they relate to the subgenera and to the better-sampled sections of $C$. subg. Sanguineae, regardless whether they were obtained from the diploids-only sample (Fig. 2A), or the diploids+polyploids sample (Fig. 2C). In the plastome trees, regardless of the sample, support for the branching order of subgenera Crataegus and Brevispinae was weak (Fig. 2A, 2C). Support, however, was strong for the sister-group relationship between subg. Mespilus and the rest of the genus (100\%). Monophyly of each of subgenera Americanae and Sanguineae was well-supported (100\%). These latter subgenera differ, however, in how much the sections they comprise are distinct from each other. Sections Douglasianae, Salignae, and Sanguineae are represented by two diploid accessions each (Table 1), and each pair has 100\% bootstrap support for both the diploids-only and the diploids+polyploids samples (Fig. 2A, 2C). Less importance was attached to the sampling of subg. Americanae, so that four of the five diploids from this subgenus each belonged to different series within $C$. sect. Coccineae (Fig. 2A; Table 1; the fifth diploid belongs to sect. Macracanthae). As a result, in the diploids-only sample there was no opportunity to form clades representing taxonomic groups, and in fact branch support for individual Americanae accessions

Peer) reviewing PDF | (2020:12:56540:2:0:NEW 30 Sep 2021) 
392

393

394

395

396

397

398

399

400

401

402

403

404

405

406

407

408

409

410

411

412

413

414

415

416

417

418

419

420

421

422

423

424

425

426

427

428

429

430

431

432

433

434

435

436

437

was $\leq 67 \%$ (Fig. 2A). Similarly, in the subg. Americanae diploids+polyploids sample there was no well-supported taxonomic structure, unlike that seen in the corresponding subg. Sanguineae sample (Fig. 2C).

Gene trees - Sequence assembly yielded alignments for the entire plastome, less one copy of the internal repeat, and for 257 low copy-number nuclear loci. The latter comprised 25 characterized as poor-quality alignments and were edited as described in the methods. Only six loci were flagged by HybPiper as containing paralogs, and these include two that were characterized as poor-quality alignments.

Twelve loci were eliminated because they lacked data for one or more terminals in the diploids-only sample. A thirteenth was eliminated from the diploids+polyploids sample for the same reason. For the sample of 14 diploid Crataegus accessions only, gene trees were considered only for the 245 nuclear loci for which all 14 accessions were represented (Supplemental Fig. S1; Supplemental Table S2). For the sample of 24 diploid and tetraploid accessions, only 244 gene trees were considered (Supplemental Fig. S1; Supplemental Table S3), for the same reason. Comparison was also made with the multilocus coalescent tree for all 244 or 245 loci (Fig. 3).

The first criterion used in tabulating and sorting the trees for the diploid accessions concerned the extent to which trees conformed to the subgeneric topology seen in earlier work (Lo \& Donoghue 2012; Lo et al. 2009a; Lo et al. 2007; Zarrei et al. 2015), and in the plastome tree (Fig. 2). In the earlier work $C$. germanica (western Eurasia) and C. brachyacantha (North America) were found to be sister to the remainder of the genus and, within that remainder, $C$. subg. Crataegus (western Eurasia) was sister to the clade comprising C. subg. Americanae (North America) and C. subg. Sanguineae (eastern Eurasia and North America). Here, however, in the plastome tree (Fig. 2; Fig. 1 in Ufimov \& Dickinson 2020) and in trees for 12 of the nuclear loci C. monogyna is sister to the remainder of the genus (e.g. Dtree17, Dtree58; Supplemental Fig. S1). In the trees for 35 loci $C$. brachyacantha was sister to the remainder of the genus (e.g. Dtree208; Supplemental Fig. S1). Crataegus germanica was sister to the remainder of the genus in 97 single locus trees (all remaining diploids-only trees in Supplemental Fig. S1), and in the multilocus trees calculated over all 244 or 245 loci (Fig. 3). In the trees for 16 loci a clade comprising $C$. germanica and $C$. brachyacantha was sister to the rest of the genus (Supplemental Table S2). In 46 trees, various Americanae and Sanguineae accessions formed two- to four-member clades with each other, or with one or more of C. brachyacantha, $C$. germanica, or C. monogyna and these were sister to the rest of the genus (Supplemental Table S2). Finally, in the 39 remaining trees the topology or the resolution made meaningful assessment of sister group relationships impractical (Supplemental Table S2). The remaining criteria, concerned with manifestation of the taxonomic structure of our sample, as seen in the topology of the single-locus trees, are discussed below.

Only 19 of the single-locus diploids-only trees showed markedly high rtCF values, exceeding the third quartile by more than $1.5 \times$ the interquartile range of these values (concordance with the plastome tree 0.573 - 0.750; Supplemental Fig. S1). These trees formed the basis for further analyses of the impact seen on the topology of the diploid-only trees from adding in the tetraploid accessions (Fig. 4; Supplemental Fig. S1), and were derived from 16 "good" and three "medium" quality alignments (Supplemental Table S1). 
438

439

440

441

442

443

444

445

446

447

448

449

450

451

452

453

454

455

456

457

458

459

460

461

462

463

464

465

466

467

468

469

470

471

472

473

474

475

476

477

478

479

480

481

482

483

Locus 95 (MDP0000220167, on chromosome 8, probable Vacuolar proton translocating ATPase 100 kDa subunit; Supplemental Fig. S1, S2; Supplemental Table S1) was the only one of these 19 loci to produce a tree for the diploid+tetraploid sample in which $C$. subg. Americanae and subg. Sanguineae were reciprocally monophyletic, demonstrating that for this alignment inclusion of the tetraploid accessions in estimating the gene phylogeny had little impact on either the topological relationships between the subgenera or on the memberships of these two clades (Supplemental Fig. S2; Supplemental Table S3). Support is high for the nodes supporting the early-diverging subgenera (Brevispinae, Crataegus). However, support is low for nodes supporting the Americanae and Sanguineae clades in both the diploids-only and the diploids+tetraploids trees (Supplemental Fig. S1, S2; Supplemental Tables S2, S3). Although the three taxonomic sections belonging to $C$. subg. Sanguineae also formed distinct subclades (compare Fig. 2 and Tree5 in Supplemental Fig. S1; Supplemental Tables S2, S3), support was nevertheless low for most of the internal nodes in these clades. In the remainder of the 19 trees the principal impact on tree structure of including the inferred Sanguineae allotetraploids and the widespread Americanae tetraploids (C. chrysocarpa, C. macracantha) was that in 16 of them one to five of the Sanguineae tetraploids were included in the Americanae clade (Supplemental Fig. $\mathrm{S} 1)$. In the trees for loci 222 and 254 one or two of the Americanae tetraploids was included in the Sanguineae clade. In several instances some Sanguineae diploids were also included in the Americanae clade (e.g. Tree179, Tree198; Supplemental Fig. S1).

Phylogenetic invariants - Calculating the amount of admixture $(\hat{\gamma}$; Table 3; Supplemental Fig. $\mathrm{S} 3$ ) from our nuclear sequence data strongly suggests that $C$. douglasii and $C$. rivularis are intersubgeneric hybrids ( $\hat{\gamma}$ values in the ranges $0.6-0.76$ and $0.69-0.77$, respectively, associated with vanishingly small $p$-values; Table 3 ). In contrast, for the putative hybrid tetraploid $C$. macracantha, support for $\mathrm{H}_{0}: \gamma=0$ was indicated by low or modest values of $\hat{\gamma}(\mathrm{P} 2=$ Americanae, 0.06; P2 = Sanguineae, 0.31), associated with correspondingly high $p$-values $(0.4$ and 1.0 , respectively).

Splits network - All of the Sanguineae tetraploid samples are represented by reticulate lines, consistent with their hybrid origin. The absence of reticulation in subgenus Americanae is an artifact of our limited sampling of this large subgenus. Diploids in subgenus Sanguineae also show reticulation presumably due to their shared ancestry with the tetraploids.

Multivariate comparisons of gene trees - Principal Coordinates analyses (PCoA) of our samples of diploids-only trees, as represented by the MV and RT distances between them (Fig. 4), demonstrate (a) clustering of the trees most closely concordant with the plastome tree; (b) dispersion along the PCo axes interpretable with respect to features of tree topology and clade composition (Supplemental Fig. S1, S2 and Supplemental Tables S2, S3); and (c) the way in which tree concordance and the distances between trees may reflect different features of the trees (Kendall et al. 2018). It is also apparent from scree plots (Supplemental Fig. S4) of the eigenvalues represented by the PCoA axes in these ordinations that the RT distances summarize the variation among our diploids-only trees in fewer dimensions (five significant axes, accounting for a total of $75 \%$ of the total variance) than was the case with the MV distances (30 significant axes, accounting for $81 \%$ of the total variance; the first five axes account for only $39 \%)$.

Peer) reviewing PDF | (2020:12:56540:2:0:NEW 30 Sep 2021) 
Multilocus trees - Both the coalescent and concatenated multilocus trees were all highly concordant with the plastome trees, whether for the diploids-only or the diploids+teraploids sample ( $\mathrm{rtCF}$ values in the ranges $0.62-0.78$, in comparisons with the corresponding subgenusand section-collapsed plastome trees; Fig. 2B, 2D). Well-supported differences between the ASTRAL-III trees (Fig. 3) and the plastome trees (Fig. 2) were restricted to branching order relationships between the early-diverging subgenera Mespilus, Brevispinae, and Crataegus (compare Fig. 2 and Fig. 3). The sister-group relationship between subgenera Americanae and Sanguineae was strongly supported, as was the monophyly of each of the three sections in subgenus Sanguineae. Sections Coccineae and Macracanthae in subgenus Americanae were not monophyletic with our sample (Fig. 3).

IQ-TREE provides not only bootstrap support values, but also gene (gCF) and site (sCF) concordances and discordances (gDF and sDF, Fig. 5; Lanfear 2018; Minh et al. 2020a; Minh et al. 2020b). These values (for the 12 nodes shared by the diploid-only and the diploid + tetraploid trees; compare Fig. 5A-C) demonstrate how inclusion of the tetraploid hybrids and their Americanae parents in trees reduces the proportion of gene trees supporting individual nodes (gCF) from 5-65\% in the diploids-only sample to $1-40 \%$ in the combined sample (Fig. 5A; Supplemental Table S4). The effect of the adding the tetraploids on the proportion of sites supporting individual nodes is much less marked, from $30-65 \%$ to $30-55 \%$ (Fig. 5A). With both types of concordance values there is a generally linear trend to the effect of adding the tetraploid accessions. In the case of the gCF values, however, four nodes show lower values than this trend would predict: 29 (monophyly of subgenus Americanae), 37 (monophyly of subgenus Sanguineae), 42 (monophyly of the two diploid C. suksdorfii individuals), and 47 (monophyly of the two diploid $C$. saligna individuals). The first two departures could be attributed to the multiplicity of topologies stemming from tetraploid individuals sharing sequences with individuals in the other subgenus. The latter two are probably linked in a similar way to diploids joining other clades because they share sequences with their allotetraploid descendants. As discussed by Lanfear (2018), the bootstrap support values for these nodes are $90-100 \%$, reflecting the large sample size (average total sequence length $424.5 \mathrm{kbp}$ per accession) and its effect on the sampling variances for these nodes. Only two of the internal nodes in the Americanae clade, and four in the Sanguineae one, have bootstrap values below 83\% (Fig. 5C, italicized support values).

Following Lanfear (2018), further examination of the gene and site concordance values makes possible a test of $\mathrm{H}_{0}$ : ILS is responsible for approximately equal numbers of genes supporting alternative topologies. With our data, ILS is rejected for only two nodes on the diploids-only IQ-TREE: the one supporting the two C. suksdorfii accessions, and the one supporting the two accessions belonging to $C$. sect. Sanguineae (nodes 25 and 27 in Fig. 5B). On the diploids + tetraploids tree (Fig. 5C), in addition to node 43 (sect. Sanguineae) $\mathrm{H}_{0}$ is rejected for nodes 33 (C. crus-galli, C. punctata, and $4 x$ C. macracantha, s11; Table 1) and 40 (three $4 x$ C. douglasii). These represent, respectively, the relative homogeneity of the sequences in the two Sanguineae accessions sampled, the heterogeneity of relationships between three accessions in undersampled subgenus Americanae, and a similar heterogeneity in topological relationships between three geographically disparate samples of allotetraploid C. douglasii. In other words, 
529

530

531

532

533

534

535

536

537

538

539

540

541

542

543

544

545

546

547

548

549

550

551

552

553

554

555

556

557

558

559

560

561

562

563

564

565

566

567

568

569

570

571

572

573

574

ruling out ILS leaves room for more than one possible explanation of relationships above a given node.

Comparing the ASTRAL-III coalescent trees (Fig. 3) with the IQ-TREE trees for the concatenated sequence data (Fig. 5), we note that the diploids-only coalescent tree (Fig. 3A) does not include the two section Sanguineae accessions in a single clade, in contrast to the diploids+tetraploids tree (Fig. 3C) and the ML trees (Fig. 5). This could perhaps be explained as a consequence of undersampling the complexity of subgenus Sanguineae. In both sets of multilocus trees support levels for the branches within the subg. Americanae clade are low (Fig. 3 , local posterior probabilities $<0.95$; Fig. 5 , markedly low gCF values).

\section{Discussion}

Our study draws attention to the diversity of tree topologies encompassed by nuclear gene trees estimated first for a sample of 14 diploid-only Crataegus (hawthorn) accessions, and then for the same diploid accessions and 10 related tetraploid accessions. Incongruence of this kind is proving to be ubiquitous in phylogenomic studies (for early examples, see Leigh et al. 2011; Rokas et al. 2003). The 245 gene trees for the diploid-only sample (244 for the mixed ploidy sample) represent the nuclear low copy number loci with complete data out of a sample of 257 loci in all obtained by target capture sequencing (Weitemier et al. 2014). For each of the same two sets of accessions we also obtained a plastome tree. The topologies of both these trees reflect the relationships between Crataegus subgenera seen in earlier molecular work (Lo et al. 2009a; Zarrei et al. 2015), as well as the morphological and biogeographic relationships between the subgenera (Ufimov \& Dickinson 2020), and so we used them as reference trees against which we compare the single (and multi-) locus nuclear trees. In this way we seek to corroborate earlier evidence for gene flow within and between subgenera (Lo et al. 2009b; Lo et al. 2010; Zarrei et al. 2014), as distinct from the effects of incomplete lineage sorting (ILS; Gitzendanner et al. 2018; Li et al. 2018; Lloyd Evans et al. 2019; Magdy et al. 2019) and possible artifacts of the sequence assembly process.

Despite the diversity of individual nuclear gene tree topologies (Fig. 4), our nuclear multilocus trees (Fig. 3) depict phylogenies very similar to our plastome trees (Fig. 2) in which the two most heavily sampled subgenera (Americanae, Sanguineae) are sister to each other, and in which their relationships with the other Crataegus subgenera are much as seen in earlier work (Lo et al. 2009a; Zarrei et al. 2015). Consistent with these previous studies, hybridization between subgenus Americanae and subgenus Sanguineae was documented for the origin of Sanguineae tetraploids, but not for a tetraploid Americanae species. Examination of the gCF and sCF values explicitly rejected a role for ILS for only a very small number of nodes. The multispecies coalescent model explicitly accounts for ILS (Rabiee et al. 2019; Zhang et al. 2018), and for this reason we consider these trees (Fig. 3) to be the most accurate estimate of phylogeny. However, the support for inter-subgeneric hybridization obtained in the HyDe analysis (Table 3) and the increased topological diversity of the diploids + tetraploids trees (Fig. 4) indicate that ILS alone cannot explain all gene tree heterogeneity. We note that our use of plastome trees as references against which to compare our trees derived from nuclear loci follows a widely accepted paradigm for discovering the occurrence of hybridization (Gitzendanner et al. 2018). 
575 Phylogeny - Our results attest to the way in which robust multilocus phylogenies can be 576 obtained from large samples of topologically diverse gene trees. Likewise, these multilocus trees

577 are congruent with the morphology- and geography-based infrageneric classification of

578 Crataegus (Table 1; Ufimov \& Dickinson 2020) supported up to now by less comprehensive

579 molecular datasets (Lo \& Donoghue 2012; Lo et al. 2009a; Lo et al. 2007; Lo et al. 2009b; Zarrei

580 et al. 2014; Zarrei et al. 2015). In addition to our results, two recent studies of Chinese Crataegus

581 (Hu et al. 2021; Wu et al. 2021) further demonstrate the utility of plastome phylogenies in

582 resolving closely related species of the genus.

583

584

585

586

587

588

589

590

591

592

593

594

595

596

597

598

599

600

601

602

603

604

605

606

607

608

609

610

611

612

613

614

615

616

617

618

619

Comparison of diploids-only gene trees - We discuss our results first with respect to the single-locus trees, the coalescent and the concatenated multilocus trees, and the plastome tree built using the diploids-only sample. The reference trees (plastome tree, Fig. 2A, coalescent tree, Fig. 3A, and concatenated tree, Fig. 5B) are highly congruent with each other in distinguishing subgenera Americanae and Sanguineae, but differ in topological details within these clades. They also differ in which of the early-arising subgenus-level groups (Brevispinae, Crataegus, Mespilus) is sister to the rest of the genus. However, only 19 of the single-locus trees (Supplemental Fig. S1) show a high degree of concordance (here, the related tips concordance, rtCF; Kendall et al. 2018), exceeding the third quartile by more than $1.5 \times$ the interquartile range of the concordance values (documentation or the boxplot function; R Core Team 2016).

The incongruence of the majority of the single-locus trees (Fig. 4A, C, E) is unlikely to be due to hybridization. Homoploid hybrids between diploid hawthorns are uncommon, and are best known for involving C. monogyna Jacq. and other species with which it is sympatric either in its native range or where it has been introduced (Christensen 1992; Christensen et al. 2014; Phipps 2005; Phipps 2015). Only three taxa in the sample studied by Lo et al. (2009a) exhibited incongruence between trees built using chloroplast loci and ones built from nuclear ones, and none of these (putative trans-Atlantic paleohybrids) is included in our samples here. The variation in the diploids-only sample single-locus gene tree topology (Fig. 4A, C, E) therefore probably arises from unknown proportions of ILS, paralogy, recombination, and the potential presence of misassembled chimeric sequences.

Comparison of diploids + tetraploids gene trees - The relatively greater dispersion of the diploids + tetraploids trees (Fig. 4B, 4D, 4F) evidently represents the effect of hybridization added to those of ILS and the other processes mentioned above. With diploids + tetraploids sample the reference trees (plastome tree, Fig. 2C, and multilocus tree, Fig. 3C) are also highly congruent in both overall topology (resembling the corresponding diploids-only trees) and in the placement of the $C$. subg. Sanguineae tetraploids with their inferred maternal parents (Fig. 3B). In the diploids + tetraploids single-locus trees corresponding to the 19 diploids-only trees that are highly congruent with the reference trees (Supplemental Fig. S1) the frequent placement of the Sanguineae allotetraploids in the $C$. subg. Americanae clade suggests that sequencing and assembly procedures have captured a sequence derived from the Americanae parent of the allotetraploid. The strong signal obtained with the admixture coefficients $(\hat{\gamma}$; Table 3 ; Supplemental Fig. S3) also supports hybridization as an explanation of gene tree incongruence, as does the morphological intermediacy of the allotetraploids (Table 2). 
620

621

622

623

624

625

626

627

628

629

630

631

632

633

634

635

636

637

638

639

640

641

642

643

644

645

646

647

648

649

650

651

652

653

654

655

656

657

658

659

660

661

662

663

664

665
In the diploids + tetraploids sample, the incongruence of the remaining 225 single-locus trees likely does result from the presence of the tetraploids (Sanguineae allotetraploids and their putative Americanae parents) together with ILS and the other processes mentioned above. As described for the diploids-only sample, the gene and site concordance and discordance values for the diploids + tetraploids multilocus tree (Fig. 5C) provide further insights. Nodes supporting clades affected by the addition of the tetraploids (nodes 29 and 37, Fig. 5C) have much reduced gCF support, suggesting that these branches as they appear in the multilocus tree are in fact now supported by many fewer individual gene trees (Fig. 5A).

Multivariate comparisons of gene trees - As others have recently found (Amenta \& Klingner 2002; Bogdanowicz et al. 2012; de Vienne et al. 2012; Gonçalves et al. 2019; Huang \& Li 2013; Huang et al. 2016; Jombart et al. 2017; Kendall et al. 2018; Richards et al. 2018), comparisons of the topologies of large numbers of gene (or other) trees is facilitated by graphical methods like principal coordinates analyses of distances depicting the resemblances of these trees with respect to cladistic relationships between the objects of study. Principal Coordinates Analysis (PCoA) is a well-known and commonly employed ordination method based on eigenanalysis of a transformed resemblance matrix (Gower 1966). Methods like PCoA (and Principal Components analysis) find successive orthogonal axes corresponding the directions in which variation in a multidimensional sample is greatest (Legendre \& Legendre 1998). For a given sample (such as either the diploid-only or diploids+tetraploids sample), some resemblance functions capture this variation in fewer such axes. Here, because our sample is taxonomically structured and the RT distance incorporates this structure (subgenera, sections), more of the variation in our two samples is captured in fewer dimensions than is the case with the distances that ignore taxonomic structure (MV, SMD). We have demonstrated the value of a phenetic approach to tree comparisons, calculating Euclidean distances between trees from three descriptors of their structure (Podani 1982), and using a more recent distance function that takes into account relationships extrinsic to the trees themselves (Kendall et al. 2018). These relationships (subgenera, sections of Crataegus) in our opinion do not contribute circularity, but rather enable us to better discern the relationships between tree topology and taxonomic structure relevant to our enquiry into the occurrence of hybridization. In contrast, the SMD, PMD, and CMD (individually or combined) are entirely agnostic with respect to these relationships. We found that PCoA of the related tree distances gave us the lowest dimensional summary of the diversity of tree topologies in both our diploids-only and diploids + tetraploids samples (RTPCoA, Fig. 4A, 4B; Supplementary Fig. S4; Legendre \& Legendre 1998). Nevertheless, the first two dimensions of all three PCoAs (Fig. 4; Supplementary Fig. S4) showed the same contrast in topological diversity between the diploids-only and diploids + tetraploids samples that we interpret as the effect, primarily, of ILS and ILS plus hybridization, respectively. We suggest that others will also find this phenetic approach useful as it generates its own insights into variation in tree structure and complements those to be gained from IQ-TREE where studies generate large numbers of gene trees.

Taxonomic, evolutionary, and biogeographic implications - Our results provide support for the infrageneric classification of Crataegus at the levels of subgenera and sections, as used here (Table 1; Ufimov \& Dickinson 2020). In response to the comments by Phipps (2016) on earlier molecular results (Lo et al. 2009a; Lo et al. 2007; Zarrei et al. 2015), we note first that the monophyly of the clade Crataegus + Mespilus is well-established by studies showing that a 
666 Hesperomeles + Crataegus + Mespilus clade ( $\mathrm{Li}$ et al. 2012) is sister to an Amelanchier clade, 667 and that this combined clade, in turn, is sister to most or all of the remaining Malinae (Liu et al. 668 2020; Lo \& Donoghue 2012). Second, we observe that our sample of gene trees (Supplemental

669 Fig. S1, S2; compare Fig. 3B, 3D) and our plastome trees (Fig. 2B, 2D) provide support for both

670 excluding or including the medlar in Crataegus. This ambivalence suggests to us that radiation

671 of hawthorns and medlars (or, of subgenera within Crataegus) occurred relatively rapidly (much

672 as with the genera of the Maleae; Campbell et al. 2007; Lo et al. 2009a), with only a single

673 species of medlar and C. brachyacantha persisting to the present, representative of their

674 respective subgenera. We note wide acceptance of the idea that taxonomic rank above the

675 species level is to a high degree arbitrary (Stevens 1997), so that given the morphological

676 similarities between $C$. germanica and some, if not all, of the remaining Crataegus species we

677 see no compelling reason to maintain two separate genera (Ufimov \& Dickinson 2020).

678

679

\section{Conclusions}

680

681

682

We have demonstrated that the topological diversity of individual low copy number nuclear gene trees that we obtained by Next Generation Sequencing can nevertheless produce well-supported

683 multilocus phylogenies, in this case for the genus Crataegus. This result, in our diploids-only

684 sample (in which evidence for hybridization is scant) suggests an important role for ILS.

685

686

687

688

689

690

691

692

693 However, admixture statistics suggest that the increased diversity attendant on including $C$. subg. Sanguineae tetraploids and their probable Americanae pollen parents together with the same diploids is due to the hybrid origin of the Sanguineae tetraploids, even if there are also effects of additional ILS in the larger sample.

These results are consistent with phylogenomic studies of other plant genera where incongruence among numerous nuclear loci has been attributed to a combination of ILS and interspecific hybridization and introgression (Bernhardt et al. 2020; Carter et al. 2019; Karimi et al. 2019; Morales-Briones et al. 2018; Murphy et al. 2020). In our study and these others, the integration

694

695

696

697

698

699

700

701

702

703

704

705

706

707

708

709

710 of species tree approaches that account for ILS, measures of gene tree discordance, and network analyses have been effectively employed to tease apart the relative contributions of these processes.

We note too that the multilocus phylogenies are highly congruent with ones we obtained from whole plastome sequences, and with a morphology-supported subgeneric classification of the genus. Our results, based on vastly more sequence data than has been available previously, support earlier ones suggesting that intersubgeneric hybridization, aided by the occurrence in Crataegus of gametophytic apomixis, has played a much more important role in Crataegus evolution than has been previously recognized. This result parallels recent observations on other large genera of Rosaceae subtribe Malinae, such as Amelanchier and Sorbus. Our conclusions concerning the roles of ILS and hybridization in Crataegus arise notably from our use of treetree comparisons and in particular from our use of a metric that employs information relevant to our enquiry, namely the infrageneric and sectional affiliations of our samples.

Liston (2014) designed probes for targeting 257 nuclear loci in Rosaceae, using apple, peach and strawberry, the three genome sequences available at that time. This is the first application of the

711 apple probes, and the $95 \%$ success rate in locus assembly demonstrates their utility. The fact that 
712 Crataegus and Malus belong to different clades of the Malinae (Liu et al. 2020; Lo \& Donoghue

713 2012) suggests that these probes will be very effective across the entire apple subtribe. An

714 increasing number of studies are relying on the "universal" for flowering plants Angiosperm-353

715 set of probes (Johnson et al. 2019) suggesting that clade-specific probes may not be necessary.

716 However, it is feasible to combine both universal and clade-specific probes in a single study

717 (Larridon et al. 2020; Shah et al. 2021; Siniscalchi et al. 2021), and this has the benefit of further

718 increasing the number of loci available for phylogenomic comparison.

719

720

\section{Acknowledgements}

721

722

723

724

725

726

727

728

729

730

731

732

733

734

735

736

737

TAD is indebted to the Arnold Arboretum of Harvard University, Jamaica Plain, Massachusetts; the Jardin Botanique de Montréal, Québec; Trey Lewis, De Soto Parish, Louisiana; and the University of California Botanical Garden at Berkeley for permission to collect Crataegus species on their properties. TAD is likewise grateful to the staff, volunteers, and (over many years) the students and other assistants at the Green Plant Herbarium (TRT) of the Royal Ontario Museum. Many of the collections could not have been made without the help of field guidance from Rebecca Dotterer, Ron Lance, Rhoda M. Love, James B. Phipps, and the late Steve Brunsfeld. Finally, TAD thanks the collectors listed in Table 1, together with David Baxter, Adam Dickinson, John Dickinson, Rodger Evans, Fannie Gervais, Graeme Hirst, Hazrah Moothoo, Sophie Nguyen, Tamra Prior, Cassandra Shaw, and Mehdi Zarrei for their assistance in the field. TRT's collection of Crataegus leaf tissue preserved with desiccating silica gel was curated by Mehdi Zarrei with the assistance of Ionatan Waisgluss. AL thanks Mark Dasenko and Brent Kronmiller of the Oregon State University Center for Genome Research and Biocomputing for sequencing and preliminary bioinformatic analysis, respectively.

738

739

740

741

742

743

744

745

746

747

748

749

750

751

752

753

754

755

756

\section{References}

Adobe_Corp. 2019. Illustrator. 24.2 ed.

Amenta N, and Klingner J. 2002. Case study: Visualizing sets of evolutionary trees. IEEE Symposium on Information Visualization 2002 INFOVIS 2002. Boston MA: IEEE. p 7174

Bankevich A, Nurk S, Antipov D, Gurevich AA, Dvorkin M, Kulikov AS, Lesin VM, Nikolenko SI, Pham S, Prjibelski AD, and others. 2012. SPAdes: a new genome assembly algorithm and its applications to single-cell sequencing. Journal of Computational Biology 19:455477.

Bernhardt N, Brassac J, Dong X, Willing E-M, Poskar CH, Kilian B, and Blattner FR. 2020. Genomewide sequence information reveals recurrent hybridization among diploid wheat wild relatives. The Plant Journal 102:493-506. https://doi.org/10.1111/tpj.14641

Blischak PD, Chifman J, Wolfe AD, and Kubatko LS. 2018. HyDe: A Python Package for Genome-Scale Hybridization Detection. Systematic Biology 67:821-829. 10.1093/sysbio/syy023

Bogdanowicz D, Giaro K, and Wróbel B. 2012. TreeCmp: Comparison of Trees in Polynomial Time. Evol Bioinform Online 8:475-487. 10.4137/EBO.S9657

Brewer CA. 2013. ColorBrewer 2.0. Available at https://colorbrewer2.org/ (accessed 20-Mar2020).

Peer] reviewing PDF | (2020:12:56540:2:0:NEW 30 Sep 2021) 
757

758

759

760

761

762

763

764

765

766

767

768

769

770

771

772

773

774

775

776

777

778

779

780

781

782

783

784

785

786

787

788

789

790

791

792

793

794

795

796

797

798

799

800

801

802

Burgess MB, Cushman KR, Doucette ET, Frye CT, and Campbell CS. 2015. Understanding diploid diversity: A first step in unraveling polyploid, apomictic complexity in Amelanchier. American Journal of Botany 102:2041-2057. doi:10.3732/ajb.1500330

Campbell CS, Burgess MB, Cushman KR, Doucette ET, Dibble AC, and Frye CT. 2015. Amelanchier. In: 1993+ FNAEC, ed. Flora of North America North of Mexico. New York and Oxford: Oxford University Press, 9:646-661.

Campbell CS, Evans RC, Morgan DR, Dickinson TA, and Arsenault MP. 2007. Phylogeny of subtribe Pyrinae (formerly the Maloideae, Rosaceae): limited resolution of a complex evolutionary history. Plant Systematics and Evolution 266:119-145.

Carter KA, Liston A, Bassil NV, Alice LA, Bushakra JM, Sutherland BL, Mockler TC, Bryant DW, and Hummer KE. 2019. Target Capture Sequencing Unravels Rubus Evolution. Frontiers in Plant Science 10. 10.3389/fpls.2019.01615

Christensen KI. 1992. Revision of Crataegus Sect. Crataegus and Nothosect. Crataeguineae (Rosaceae-Maloideae) in the Old World. Systematic Botany Monographs 35:1-199.

Christensen KI, Zarrei M, Kuzmina M, Talent N, Lin C, and Dickinson TA. 2014. Crataegus $\times$ ninae-celottiae and C. $\times$ cogswellii (Rosaceae, Maleae), two spontaneously formed intersectional nothospecies. Phytokeys 36:1-26. 10.3897/phytokeys.36.6784

Coughlan JM. 2012. Mechanisms for range size and distribution variation in polyploidy complex black-fruited hawthorn (Crataegus series Douglasianae): biogeographic implications for the maintenance of cytotype diversity. M.Sc. University of Toronto.

Coughlan JM, Han S, Stefanović S, and Dickinson TA. 2017. Widespread generalist clones are associated with range and niche expansion in allopolyploids of Pacific Northwest Hawthorns (Crataegus L.). Molecular Ecology 26:5484-5499. 10.1111/mec.14331

Coughlan JM, Stefanović S, and Dickinson TA. 2014. Relative resource allocation to dispersal and competition demonstrates the putative role of hybridity in geographical parthenogenesis. Journal of Biogeography 41:1603-1613. 10.1111/jbi.12316

Cushman KR, Burgess MB, Doucette ET, Nelson GA, and Campbell CS. 2017. Species Delimitation in Tetraploid, Apomictic Amelanchier (Rosaceae). Systematic Botany 42:234-256.

Daccord N, Celton JM, Linsmith G, Becker C, Choisne N, Schijlen E, van de Geest H, Bianco L, Micheletti D, Velasco R, Di Pierro EA, Gouzy J, Rees DJG, Guérif P, Muranty H, Durel CE, Laurens F, Lespinasse Y, Gaillard S, Aubourg S, Quesneville H, Weigel D, van de Weg E, Troggio M, and Bucher E. 2017. High-quality de novo assembly of the apple genome and methylome dynamics of early fruit development. Nature Genetics 49:10991106.

de Vienne DM, Ollier S, and Aguileta G. 2012. Phylo-MCOA: A Fast and Efficient Method to Detect Outlier Genes and Species in Phylogenomics Using Multiple Co-inertia Analysis. Molecular Biology and Evolution 29:1587-1598. 10.1093/molbev/msr317

Deng W. 2007. Fasta2Phylip.pl. Available at https://indra.mullins.microbiol.washington.edu/perlscript/docs/Sequence.html (accessed 11-Feb-2020).

Dickinson TA. 2018. Sex and Rosaceae apomicts. Taxon 67:1093-1107.

Dickinson TA, Belaoussoff S, Love RM, and Muniyamma M. 1996. North American blackfruited hawthorns: I. Variation in floral construction, breeding system correlates, and their possible evolutionary significance in Crataegus sect. Douglasii Loudon. Folia Geobotanica \& Phytotaxonomica 31:355-371.

Peer] reviewing PDF | (2020:12:56540:2:0:NEW 30 Sep 2021) 
803 Dickinson TA, Coughlan JM, and Han S. in prep.-a. [North American black-fruited hawthorns

804 IV.] What IS Suksdorf's hawthorn? - reexamining the black-fruited hawthorns of the

805

806

807

808

809

810

811

812

813

814

815

816

817

818

819

820

821

822

823

824

825

826

827

828

829

830

831

832

833

834

835

836

837

838

839

840

841

842

843

844

845

846 Pacific Northwest (Crataegus section Douglasianae, Rosaceae tribe Maleae)

Dickinson TA, Yan XQ, Han S, and Zarrei M. in prep.-b. Polyploidy, niche shifts, hybridization, and geographic parthenogenesis in Rocky Mountain black-fruited hawthorns (Crataegus L., Rosaceae).

Dickinson TA, Lo EYY, Talent N, and Love RM. 2008. Black-fruited Hawthorns of Western North America - one or more Agamic Complexes? Botany 86:846-865. 10.1139/B08-072

Dickinson TA, and Love RM. 1997. [North American black-fruited hawthorns: III.] What IS Douglas hawthorn? In: Kaye T, Liston A, Love RM, Luoma DL, Meinke RJ, and Wilson MV, eds. Conservation and Management of Oregon's Native Flora. Corvallis OR: Native Plant Society of Oregon, 162-171.

Doyle JJ. 2021. Defining Coalescent Genes: Theory Meets Practice in Organelle Phylogenomics. Systematic Biology. 10.1093/sysbio/syab053.

Evans RC, and Dickinson TA. 1996. North American black-fruited hawthorns II. Floral development of 10- and 20-stamen morphotypes in Crataegus section Douglasii (Rosaceae: Maloideae). American Journal of Botany 83:961-978.

Felsenstein J. 2005. The Newick tree format. Available at http://evolution.genetics.washington.edu/phylip/newicktree.html (accessed 9 September 2019).

Frontier S. 1976. Étude de la décroissance des valeurs propres dans une analyses en composantes principales: comparaison avec le modèle du bâton brisé. Journal of Experimental Marine Biology and Ecology Ecol 25:67-75.

Gitzendanner MA, Soltis PS, Yi T-S, Li D-Z, and Soltis DE. 2018. Chapter Ten - Plastome Phylogenetics: 30 Years of Inferences Into Plant Evolution. In: Chaw S-M, and Jansen RK, eds. Advances in Botanical Research: Academic Press, 293-313.

Gonçalves DJP, Simpson BB, Ortiz EM, Shimizu GH, and Jansen RK. 2019. Incongruence between gene trees and species trees and phylogenetic signal variation in plastid genes. Molecular Phylogenetics and Evolution 138:219-232. https://doi.org/10.1016/j.ympev.2019.05.022

Gower JC. 1966. Some distance properties of latent root and vector methods used in multivariate analysis. Biometrika 53:325-338.

Guindon S, Dufayard J-F, Lefort V, Anisimova M, Hordijk W, and Gascuel O. 2010. New Algorithms and Methods to Estimate Maximum-Likelihood Phylogenies: Assessing the Performance of PhyML 3.0. Systematic Biology 59:307-321. 10.1093/sysbio/syq010

Haines A. 2011. Flora Novae Angliae - A manual for identification of native and naturalized higher vascular plants of New England. New Haven: New England Wildflower Society \& Yale University Press New Haven \& London.

Hamston TJ, de_Vere N, King RA, Pellicer J, Fay MF, Cresswell JE, and Stevens JR. 2018. Apomixis and Hybridization Drives Reticulate Evolution and Phyletic Differentiation in Sorbus L.: Implications for Conservation. Frontiers in Plant Science 9:1796. 10.3389/fpls.2018.01796

Hartigan JA. 1967. Representation of Similarity Matrices by Trees. Journal of the American Statistical Association 62:1140-1158. 
847 Hoang DT, Chernomor O, von Haeseler A, Minh BQ, and Vinh LS. 2018. UFBoot2: Improving

848

849

850

851

852

853

854

855

856

857

858

859

860

861

862

863

864

865

866

867

868

869

870

871

872

873

874

875

876

877

878

879

880

881

882

883

884

885

886

887

888

889

890

891 the Ultrafast Bootstrap Approximation. Molecular Biology and Evolution 35:518-522. $10.1093 / \mathrm{molbev} / \mathrm{msx} 281$

Hu G, Wang Y, Wang Y, Zheng S, Dong W, Dong N. 2021. New Insight into the Phylogeny and Taxonomy of Cultivated and Related Species of Crataegus in China, Based on Complete Chloroplast Genome Sequencing. Horticulturae 7:301. 10.3390/horticulturae7090301.

Huang H, and Li Y. 2013. MASTtreedist: Visualization of Tree Space Based on Maximum Agreement Subtree. Journal of Computational Biology 20:42-49. 10.1089/cmb.2012.0243

Huang W, Zhou G, Marchand M, Ash JR, Morris D, Van Dooren P, Brown JM, Gallivan KA, and Wilgenbusch JC. 2016. TreeScaper: Visualizing and Extracting Phylogenetic Signal from Sets of Trees. Molecular Biology and Evolution 33:3314-3316. 10.1093/molbev/msw 196

Huson DH, and Bryant D. 2005. Application of Phylogenetic Networks in Evolutionary Studies. Molecular Biology and Evolution 23:254-267. 10.1093/molbev/msj030

Johnson MG, Gardner EM, Liu Y, Medina R, Goffinet B, Shaw AJ, Zerega NJ, and Wickett NJ. 2016. HybPiper: Extracting coding sequence and introns for phylogenetics from highthroughput sequencing reads using target enrichment. Applications in Plant Sciences 4:1600016.

Johnson MG, Pokorny L, Dodsworth S, Botigué LR, Cowan RS, Devault A, Eiserhardt WL, Epitawalage N, Forest F, Kim JT, Leebens-Mack JH, Leitch IJ, Maurin O, Soltis DE, Soltis PS, Wong GK-s, Baker WJ, and Wickett NJ. 2019. A Universal Probe Set for Targeted Sequencing of 353 Nuclear Genes from Any Flowering Plant Designed Using k-Medoids Clustering. Systematic Biology 68:594-606. 10.1093/sysbio/syy086

Jombart T, Kendall M, Almagro-Garcia J, and Colijn C. 2017. TREESPACE: Statistical exploration of landscapes of phylogenetic trees. Molecular Ecology Resources 17:13851392. 10.1111/1755-0998.12676

Jung S, Lee T, Cheng C-H, Buble K, Zheng P, Yu J, Humann J, Ficklin SP, Gasic K, Scott K, Frank M, Ru S, Hough H, Evans K, Peace C, Olmstead M, DeVetter LW, McFerson J, Coe M, Wegrzyn JL, Staton ME, Abbott AG, and Main D. 2019. 15 years of GDR: New data and functionality in the Genome Database for Rosaceae. Nucleic Acids Research 47:D1137-D1145. 10.1093/nar/gky1000

Kabacoff RI. 2017. Quick-R - Histograms and Density Plots. Available at https://www.statmethods.net/graphs/density.html (accessed 18-Feb-2020).

Kalyaanamoorthy S, Minh BQ, Wong TKF, von Haeseler A, and Jermiin LS. 2017. ModelFinder: Fast model selection for accurate phylogenetic estimates. Nature Methods 14:587-589. https://doi.org/10.1038/nmeth.4285

Kamneva OK, Syring J, Liston A, and Rosenberg NA. 2017. Evaluating allopolyploid origins in strawberries (Fragaria) using haplotypes generated from target capture sequencing. BMC Evolutionary Biology 17:180. 10.1186/s12862-017-1019-7

Karimi N, Grover CE, Gallagher JP, Wendel JF, Ané C, and Baum DA. 2019. Reticulate Evolution Helps Explain Apparent Homoplasy in Floral Biology and Pollination in Baobabs (Adansonia; Bombacoideae; Malvaceae). Systematic Biology 69:462-478. 10.1093/sysbio/syz073 
892 Kates HR, Johnson MG, Gardner EM, Zerega NJC, and Wickett NJ. 2018. Allele phasing has minimal

893

894

895

896

897

898

899

900

901

902

903

904

905

906

907

908

909

910

911

912

913

914

915

916

917

918

919

920

921

922

923

924

925

926

927

928

929

930

931

932

933

934

935 impact on phylogenetic reconstruction from targeted nuclear gene sequences in a case study of Artocarpus. American Journal of Botany 105:404-416. https://doi.org/10.1002/ajb2.1068

Katoh K, and Standley DM. 2013. MAFFT multiple sequence alignment software version 7: improvements in performance and usability. Molecular Biology and Evolution 30:772780.

Kearse M, Moir R, Wilson A, Stones-Havas S, Cheung M, Sturrock S, Buxton S, Cooper A, Markowitz S, Duran C, Thierer T, Ashton B, Meintjes P, and Drummond A. 2012. Geneious Basic: An integrated and extendable desktop software platform for the organization and analysis of sequence data. Bioinformatics 28:1647-1649. 10.1093/bioinformatics/bts 199

Kendall M. 2019. Comparing trees by tip label categories. Available at https://cran.rproject.org/web/packages/treespace/vignettes/tipCategories.html (accessed 15-Jun2019).

Kendall M, Eldholm V, and Colijn C. 2018. Comparing phylogenetic trees according to tip label categories. bioRxiv:251710. 10.1101/251710

Kent WJ. 2002. BLAT - the BLAST-like alignment tool. Genome Research 12:656-664.

Kurtto A, Sennikov A, and Lampinen R. 2013. Atlas Flora Europaeae. Distribution of Vascular Plants in Europe. 16. Rosaceae (Cydonia to Prunus, excl. Sorbus). Helsinki: The Committee for Mapping the Flora of Europe \& Societas Biologica Fennica Vanamo.

Lance RW. 2014. Haws: A Guide to Hawthorns of the Southeastern United States. Mills River $\mathrm{NC}$ : By the author.

Lanfear R. 2018. Calculating and interpreting gene- and site-concordance factors in phylogenomics. Available at http://www.robertlanfear.com/blog/files/concordance_factors.html (accessed 15 September 2019).

Larridon I, Villaverde T, Zuntini AR, Pokorny L, Brewer GE, Epitawalage N, Fairlie I, Hahn M, Kim J, Maguilla E, Maurin O, Xanthos M, Hipp AL, Forest F, and Baker WJ. 2020. Tackling Rapid Radiations with Targeted Sequencing. Frontiers in Plant Science 10. 10.3389/fpls.2019.01655

Legendre L, and Legendre P. 1998. Numerical Ecology. In: Jorgensen SE, ed. Developments in Environmental Modelling. 2nd ed. Amsterdam: Elsevier Scientific Publishing Company, 419.

Leigh JW, Lapointe F-J, Lopez P, and Bapteste E. 2011. Evaluating Phylogenetic Congruence in the Post-Genomic Era. Genome Biology and Evolution 3:571-587. 10.1093/gbe/evr050

Li F, Fan Q, Li Q, Chen S, Guo W, Cui D, and Liao W. 2014. Molecular phylogeny of Cotoneaster (Rosaceae) inferred from nuclear ITS and multiple chloroplast sequences. Plant Systematics and Evolution 300:1533-1546. 10.1007/s00606-014-0980-5

Li M, Chen S, Zhou R, Fan Q, Li F, and Liao W. 2017. Molecular Evidence for Natural Hybridization between Cotoneaster dielsianus and C. glaucophyllus. Frontiers in Plant Science 8:704. 10.3389/fpls.2017.00704

Li Q-Y, Guo W, Liao W-B, Macklin JA, and Li J-H. 2012. Generic limits of Pyrinae: Insights from nuclear ribosomal DNA sequences. Botanical Studies 53:151-164.

Li Y, Yang Y, Yu L, Du X, and Ren G. 2018. Plastomes of nine hornbeams and phylogenetic implications. Ecology and Evolution 8:8770-8778. 10.1002/ece3.4414 
936

937

938

939

940

941

942

943

944

945

946

947

948

949

950

951

952

953

954

955

956

957

958

959

960

961

962

963

964

965

966

967

968

969

970

971

972

973

974

975

976

977

978

979

980
Liston A. 2014. 257 nuclear genes for Rosaceae phylogenomics. Available at https://figshare.com/articles/257_nuclear_genes_for_Rosaceae_phylogenomics/1060394 (accessed 19-Jan-2016).

Liu B-B, Campbell CS, Hong D-Y, and Wen J. 2020. Phylogenetic relationships and chloroplast capture in the Amelanchier-Malacomeles-Peraphyllum clade (Maleae, Rosaceae): evidence from chloroplast genome and nuclear ribosomal DNA data using genome skimming. Molecular Phylogenetics and Evolution:106784. https://doi.org/10.1016/j.ympev.2020.106784

Lloyd Evans D, Joshi SV, and Wang J. 2019. Whole chloroplast genome and gene locus phylogenies reveal the taxonomic placement and relationship of Tripidium (Panicoideae: Andropogoneae) to sugarcane. BMC Evolutionary Biology 19:33. 10.1186/s12862-0191356-9

Lo EYY, and Donoghue MJ. 2012. Expanded phylogenetic and dating analyses of the apples and their relatives (Pyreae, Rosaceae). Molecular Phylogenetics \& Evolution 63:230-243.

Lo EYY, Stefanović S, Christensen KI, and Dickinson TA. 2009a. Evidence for genetic association between East Asian and Western North American Crataegus L. (Rosaceae) and rapid divergence of the Eastern North American lineages based on multiple DNA sequences. Molecular Phylogenetics \& Evolution 51:157-168. doi:10.1016/j.ympev.2009.01.018

Lo EYY, Stefanović S, and Dickinson TA. 2007. Molecular reappraisal of relationships between Crataegus and Mespilus (Rosaceae, Pyreae) - two genera or one? Systematic Botany 32:596-616.

Lo EYY, Stefanović S, and Dickinson TA. 2009b. Population genetic structure of diploid sexual and polyploid apomictic hawthorns (Crataegus; Rosaceae) in the Pacific Northwest. Molecular Ecology 18:1145-1160. 10.1111/j.1365-294X.2009.04091.x

Lo EYY, Stefanović S, and Dickinson TA. 2010. Reconstructing reticulation history in a phylogenetic framework and the potential of allopatric speciation driven by polyploidy in an agamic complex in Crataegus (Rosaceae). Evolution 64:3593-3608. 10.1111/j.15585646.2010.01063.x

Lo EYY, Stefanović S, and Dickinson TA. 2013. Geographical parthenogenesis in Pacific Northwest hawthorns (Crataegus; Rosaceae). Botany 91:107-116. 10.1139/cjb-20120073

Loudon JC. 1838. Arboretum et fruticetum brittanicum, vol. 2. London: Longman, Orme, Brown, Green, and Longmans.

Mabberley DJ. 2008. Mabberley's plant book - a portable dictionary of plants, their classification and uses. Cambridge University Press, Cambridge, xviii+1021 pp.

Magdy M, Ou L, Yu H, Chen R, Zhou Y, Hassan H, Feng B, Taitano N, van der Knaap E, Zou X, Li F, and Ouyang B. 2019. Pan-plastome approach empowers the assessment of genetic variation in cultivated Capsicum species. Horticulture Research 6:108. 10.1038/s41438-019-0191-x

Martin M. 2011. Cutadapt removes adapter sequences from high-throughput sequencing reads. Available at http://journal.embnet.org/index.php/embnetjournal/article/view/200 (accessed 9-Feb-2018).

Minh BQ, Hahn MW, and Lanfear R. 2020a. New methods to calculate concordance factors for phylogenomic datasets. Molecular Biology and Evolution. 10.1093/molbev/msaa106

Peer] reviewing PDF | (2020:12:56540:2:0:NEW 30 Sep 2021) 
981

982

983

984

985

986

987

988

989

990

991

992

993

994

995

996

997

998

999

1000

1001

1002

1003

1004

1005

1006

1007

1008

1009

1010

1011

1012

1013

1014

1015

1016

1017

1018

1019

1020

1021

1022

1023

1024

1025
Minh BQ, Trifinopoulos J, Schrempf D, and Schmidt HA. 2020b. IQ-TREE version 2.0: Tutorials and Manual Phylogenomic software by maximum likelihood. Vienna: University of Vienna. p 134.

Morales-Briones DF, Liston A, and Tank DC. 2018. Phylogenomic analyses reveal a deep history of hybridization and polyploidy in the Neotropical genus Lachemilla (Rosaceae). New Phytologist 218:1668-1684.

Murphy B, Forest F, Barraclough T, Rosindell J, Bellot S, Cowan R, Golos M, Jebb M, and Cheek M. 2020. A phylogenomic analysis of Nepenthes (Nepenthaceae). Molecular Phylogenetics and Evolution 144:106668. https://doi.org/10.1016/j.ympev.2019.106668

Németh C, Papp N, Nosková J, and Höhn M. 2020. Speciation by triparental hybridization in genus Sorbus (Rosaceae). Biologia Futura 71:209-222. 10.1007/s42977-020-00003-X

Nguyen L-T, Schmidt HA, von Haeseler A, and Minh BQ. 2015. IQ-TREE: A Fast and Effective Stochastic Algorithm for Estimating Maximum-Likelihood Phylogenies. Molecular Biology and Evolution 32:268-274. 10.1093/molbev/msu300

Nylander JAA. 2020. catfasta2phyml (perl script). Available at https://github.com/nylander/catfasta2phymlcatfasta2phyml (accessed year-month-day (Aaron supply).

Palmer EJ. 1925. Synopsis of North American Crataegi. Journal of the Arnold Arboretum 6:5128.

Paradis E, Blomberg S, Bolker B, Claude J, Cuong HS, Desper R, Didier G, Durand B, Dutheil J, Gascuel O, Heibl C, Lawson D, Lefort V, Legendre P, Lemon J, McCloskey R, Nylander J, Opgen-Rhein R, Popescu A-A, Royer-Carenzi M, Schliep K, Strimmer K, and de_Vienne D. 2015. Package 'ape' (Analyses of Phylogenetics and Evolution). Available at https://cran.r-project.org/web/packages/cluster/cluster.pdf.

Phipps JB. 1988. Crataegus (Maloideae, Rosaceae) of the southeastern United States, I. Introduction and series Aestivales. Journal of the Arnold Arboretum 69:401-431.

Phipps JB. 2005. A review of hybridization in north American hawthorns - Another look at "the Crataegus problem"'. Annals of the Missouri Botanical Garden 92:113-126.

Phipps JB. 2013. Crataegus tenuior (Rosaceae) — an intriguing new species from the Okanagan of British Columbia and Washington and a new variety of C. okanaganensis. Journal of the Botanical Research Institute of Texas 7:275-297.

Phipps JB. 2015. Crataegus. In: 1993+ FNAEC, ed. Flora of North America North of Mexico. New York and Oxford: Oxford University Press, 491-643.

Phipps JB. 2016. Studies In Mespilus, Crataegus, and ×Crataemespilus (Rosaceae), I. Differentiation of Mespilus and Crataegus, Expansion of $\times$ Crataemespilus, with supplementary observations on differences between the Crataegus and Amelanchier clades. Phytotaxa 257:201-229.

Podani J. 1982. Spatial processes in the analysis of vegetation Ph.D. University of Western Ontario.

Podani J. 1993. SYN-TAX-pc Computer programs for multivariate analysis in ecology and systematics, Version 5.0 User's Guide. Budapest: Scientia Publishing.

Podani J. 2000. Simulation of random dendrograms and comparison tests: Some comments. Journal of Classification 17:123-142.

Podani J, and Dickinson TA. 1984. Comparison of dendrograms: a multivariate approach. Canadian Journal of Botany 62:2765-2778.

Peer) reviewing PDF | (2020:12:56540:2:0:NEW 30 Sep 2021) 
1026 Potter D, Eriksson T, Evans RC, Oh S, Smedmark JEE, Morgan DR, Kerr M, Robertson KR,

1027

1028

1029

1030

1031

1032

1033

1034

1035

1036

1037

1038

1039

1040

1041

1042

1043

1044

1045

1046

1047

1048

1049

1050

1051

1052

1053

1054

1055

1056

1057

1058

1059

1060

1061

1062

1063

1064

1065

1066

1067

1068

1069

1070

Arsenault M, Dickinson TA, and Campbell CS. 2007. Phylogeny and classification of Rosaceae. Plant Systematics and Evolution 266:5-43.

R Core Team. 2016. R: A language and environment for statistical computing. In: R Core Team (2016). R: A language and environment for statistical computing. R Foundation for Statistical Computing V, Austria. URL https://www.R-project.org/, editor. Vienna, Austria: R Foundation for Statistical Computing.

Rabiee M, Sayyari E, and Mirarab S. 2019. Multi-allele species reconstruction using ASTRAL. Molecular Phylogenetics \& Evolution 130:286-296. https://doi.org/10.1016/j.ympev.2018.10.033

Ralph P, Thornton K, and Kelleher J. 2020. Efficiently Summarizing Relationships in Large Samples: A General Duality Between Statistics of Genealogies and Genomes. Genetics 215:779-797. 10.1534/genetics. 120.303253

Richards EJ, Brown JM, Barley AJ, Chong RA, and Thomson RC. 2018. Variation Across Mitochondrial Gene Trees Provides Evidence for Systematic Error: How Much Gene Tree Variation Is Biological? Systematic Biology 67:847-860. 10.1093/sysbio/syy013

Rokas A, Williams BL, King N, and Carroll SB. 2003. Genome-scale approaches to resolving incongruence in molecular phylogenies. Nature 425:798-804. 10.1038/nature02053

Rothfels CJ. 2021. Polyploid phylogenetics. New Phytologist 230:66-72. https://doi.org/10.1111/nph.17105

Sayyari E, and Mirarab S. 2016. Fast Coalescent-Based Computation of Local Branch Support from Quartet Frequencies. Molecular Biology and Evolution 33:1654-1668. 10.1093/molbev/msw079

Schneider CK. 1906. Illustriertes Handbuch der Laubholzkunde. Jena: Gustav Fischer.

Shah T, Schneider JV, Zizka G, Maurin O, Baker W, Forest F, Brewer GE, Savolainen V, Darbyshire I, and Larridon I. Joining forces in Ochnaceae phylogenomics: a tale of two targeted sequencing probe kits. American Journal of Botany n/a. https://doi.org/10.1002/ajb2.1682

Shulaev V, Sargent DJ, Crowhurst RN, Mockler TC, Folkerts O, Delcher AL, Jaiswal P, Mockaitis K, Liston A, and Mane SP. 2010. The genome of woodland strawberry (Fragaria vesca). Nature Genetics 43:109-116.

Siniscalchi CM, Hidalgo O, Palazzesi L, Pellicer J, Pokorny L, Maurin O, Leitch IJ, Forest F, Baker WJ, and Mandel JR. Lineage-specific vs. universal: A comparison of the Compositae1061 and Angiosperms353 enrichment panels in the sunflower family. Applications in Plant Sciences n/a. https://doi.org/10.1002/aps3.11422

Stevens PF. 1997. How to interpret botanical classifications - suggestions from history. Bioscience 47:243-250. 10.2307/1313078

Talavera G, and Castresana J. 2007. Improvement of phylogenies after removing divergent and ambiguously aligned blocks from protein sequence alignments. Systematic Biology 56:564-577.

Talent N, and Dickinson TA. 2005. Polyploidy in Crataegus and Mespilus (Rosaceae, Maloideae): evolutionary inferences from flow cytometry of nuclear DNA amounts. Canadian Journal of Botany 83:1268-1304.

Than C, Ruths D, and Nakhleh L. 2008. PhyloNet: A Software Package for Analyzing and Reconstructing Reticulate Evolutionary Relationships. BMC Bioinformatics 9:322. https://doi.org/10.1186/1471-2105-9-322

Peer) reviewing PDF | (2020:12:56540:2:0:NEW 30 Sep 2021) 
1071 Tropicos.org. 2021. Tropicos v3.2.3 Missouri Botanical Garden. Available at

1072 http://www.tropicos.org/(accessed 03-Jul-2021).

1073

1074

1075

1076

1077

1078

1079

1080

1081

1082

1083

1084

1085

1086

1087

1088

1089

1090

1091

1092

1093

1094

1095

1096

1097

1098

1099

1100

1101

1102

1103

1104

1105

1106

1107

1108

1109

1110

1111

1112

1113

1114

1115

Ufimov RA. 2013. Notes on the genus Crataegus L. (Rosaceae). Novosti sistematiki vysshikh rastenii 44:113-125.

Ufimov RA, and Dickinson TA. 2020. Infrageneric nomenclature adjustments in Crataegus L. (Maleae, Rosaceae). Phytologia 102:177-199.

Ufimov RA, Zeisek V, Píšová S, Baker WJ, Fér T, Loo M van, Dobeš C, Schmick1 R. 2021. Relative performance of customized and universal probe sets in target enrichment: A case study in subtribe Malinae. Applications in Plant Sciences 9:e11442.10.1002/aps3.11442.

Velasco R, Zharkikh A, Affourtit J, Dhingra A, Cestaro A, Kalyanaraman A, Fontana P, Bhatnagar SK, Troggio M, Pruss D, Salvi S, Pindo M, Baldi P, Castelletti S, Cavaiuolo M, Coppola G, Costa F, Cova V, Dal Ri A, Goremykin V, Komjanc M, Longhi S, Magnago P, Malacarne G, Malnoy M, Micheletti D, Moretto M, Perazzolli M, SiAmmour A, Vezzulli S, Zini E, Eldredge G, Fitzgerald LM, Gutin N, Lanchbury J, Macalma T, Mitchell JT, Reid J, Wardell B, Kodira C, Chen Z, Desany B, Niazi F, Palmer M, Koepke T, Jiwan D, Schaeffer S, Krishnan V, Wu C, Chu VT, King ST, Vick J, Tao Q, Mraz A, Stormo A, Stormo K, Bogden R, Ederle D, Stella A, Vecchietti A, Kater MM, Masiero S, Lasserre P, Lespinasse Y, Allan AC, Bus V, Chagne D, Crowhurst RN, Gleave AP, Lavezzo E, Fawcett JA, Proost S, Rouze P, Sterck L, Toppo S, Lazzari B, Hellens RP, Durel C-E, Gutin A, Bumgarner RE, Gardiner SE, Skolnick M, Egholm M, Van de Peer Y, Salamini F, and Viola R. 2010. The genome of the domesticated apple (Malus [times] domestica Borkh.). Nature Genetics 42:833-839. http://www.nature.com/ng/journal/v42/n10/abs/ng.654.html\#supplementary-information

Weitemier K, Straub SC, Cronn RC, Fishbein M, Schmickl R, McDonnell A, and Liston A. 2014. Hyb-Seq: Combining target enrichment and genome skimming for plant phylogenomics. Applications in Plant Sciences 2:1400042.

Wu L, Cui Y, Wang Q, Xu Z, Wang Y, Lin Y, Song J, Yao H. 2021. Identification and phylogenetic analysis of five Crataegus species (Rosaceae) based on complete chloroplast genomes. Planta 254:14. 10.1007/s00425-021-03667-4.

Xiang Y, Huang C-H, Hu Y, Wen J, Li S, Yi T, Chen H, Xiang J, and Ma H. 2017. Evolution of Rosaceae fruit types based on nuclear phylogeny in the context of geological times and genome duplication. Molecular Biology and Evolution 34:262-281. doi:10.1093/molbev/msw242

Zarrei M, Stefanović S, and Dickinson TA. 2014. Reticulate evolution in North American blackfruited hawthorns (Crataegus section Douglasia; Rosaceae): evidence from nuclear ITS2 and plastid sequences. Annals of Botany 114:253-269. 10.1093/aob/mcu116

Zarrei M, Talent N, Kuzmina M, Lee J, Lund J, Shipley PR, Stefanović S, and Dickinson TA. 2015. Universal plant DNA barcode loci are poor indicators of species diversity in hawthorns (Crataegus; Rosaceae). AoB Plants 7: plv045 10.1093/aobpla/plv045

Zhang C, Rabiee M, Sayyari E, and Mirarab S. 2018. ASTRAL-III: polynomial time species tree reconstruction from partially resolved gene trees. BMC Informatics 19:153.

Zhang L, Hu J, Han X, Li J, Gao Y, Richards CM, Zhang C, Tian Y, Liu G, Gul H, Wang D, Tian Y, Yang C, Meng M, Yuan G, Kang G, Wu Y, Wang K, Zhang H, Wang D, and Cong P. 2019. A high-quality apple genome assembly reveals the association of a retrotransposon and red fruit colour. Nature communications 10:1494-1494. $10.1038 / \mathrm{s} 41467-019-09518-\mathrm{x}$

Peer) reviewing PDF | (2020:12:56540:2:0:NEW 30 Sep 2021) 
1116 Zhang J. 2017. phylotools: Phylogenetic Tools for Eco-Phylogenetics. R package version 0.2.2.

$1117 \quad$ Available at https://cran.r-project.org/web/packages/phylotools/phylotools.pdf(accessed 29-Jun1118 2021).

1119 Zhang S-D, Jin J-J, Chen S-Y, Chase MW, Soltis DE, Li H-T, Yang J-B, Li D-Z, and Yi T-S.

1120 2017. Diversification of Rosaceae since the Late Cretaceous based on plastid

$1121 \quad$ phylogenomics. New Phytologist 214:1355-1367. 10.1111/nph.14461 


\section{Figure 1}

Splits network representation of 24 hawthorn individuals based on uncorrected pdistances between aligned sequences for 244 nuclear loci (529,827 positions).

Individuals are labeled with accession number (s00) + species + Section (Aaaa) as in Table 1. Labels also indicate ploidy level if tetraploid ( $4 x, x=17$; otherwise diploid; Table 1). Crataegus subgenera shown in color. Outgroup provided by the genome of apple (Malus $\times$ domestica Borkh.; Velasco et al. 2010). Network fit $=97 \%$. Diagram produced with SplitsTree4 (Huson \& Bryant 2005) and ColorBrewer 2.0 (Brewer 2013).

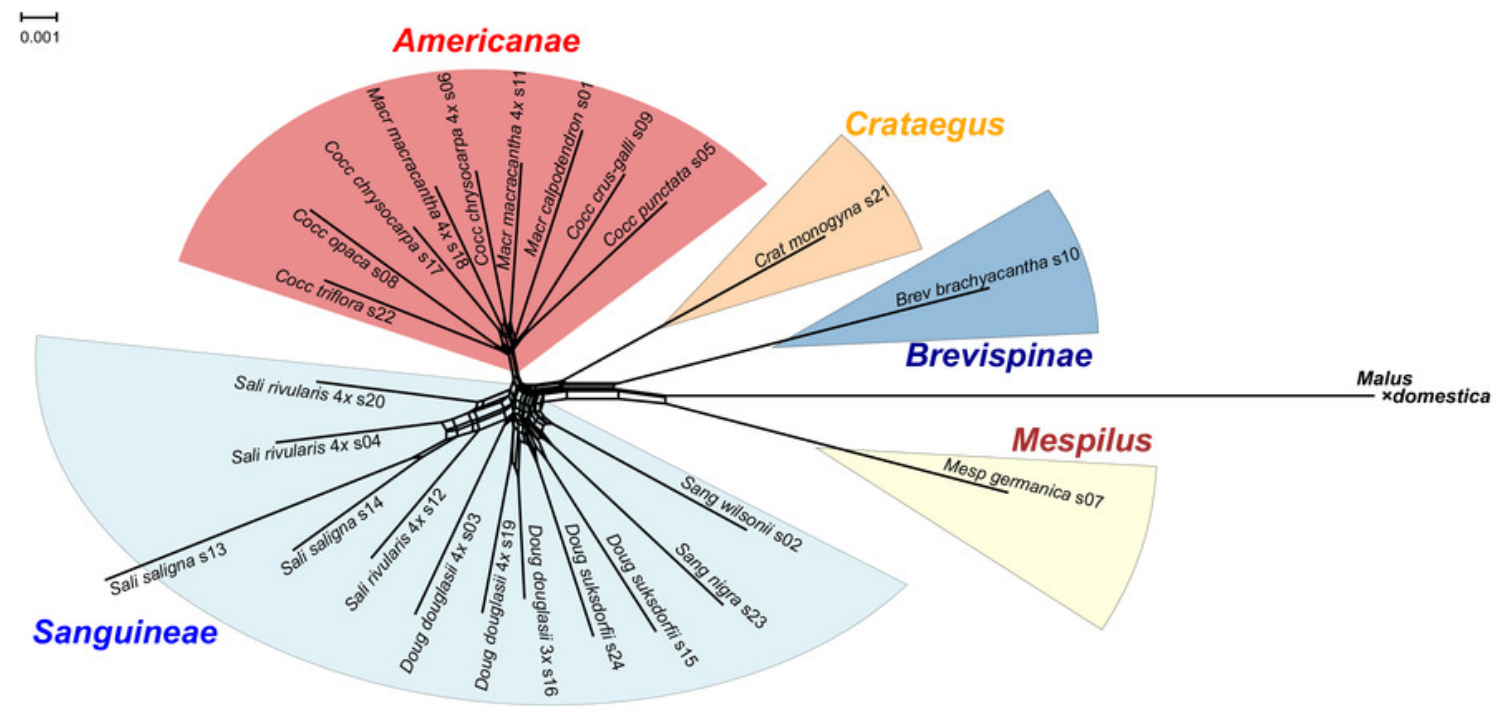




\section{Figure 2}

Crataegus infrageneric classification and impact on tree topology of including allotetraploids in a plastome phylogeny.

(A) The RAXML plastome tree for 14 diploid Crataegus accessions (numbered as in Table 1) coded to show subgenera (MESP, BREV, CRAT, AMER, SANG) and sections (color): Crataegus (Crat), Brevispinae (Brev), Mespilus (Mesp), Coccineae (Cocc), Macracanthae (Macr), Salignae (Sali), Douglasianae (Doug), and Sanguineae (series Sanguineae and Nigrae). (B) The plastome tree in (A) collapsed so as to show the topological relationships between the five subgenera. (C) The RAXML plastome tree for the same 14 diploid and 10 related tetraploid Crataegus accessions (Table 1). (D) The plastome tree in (C) collapsed so as to show the eight taxonomic sections of Crataegus represented in our sample. In (B) and (D) subgenera are color-coded as in Fig. 1. All trees have been rooted using the plastome of apple, Malus $x$ domestica (Velasco et al. 2010). In (B) and (D), collapsing was done using the function makeCollapsedTree in the R package treespace (Jombart et al. 2017). Nodes have bootstrap support $\geq 96 \%$ (diploids only) or $\geq 95 \%$ (diploids + tetraploids) unless indicated otherwise $(*)$; scale bars for branch lengths are in substitution units. 

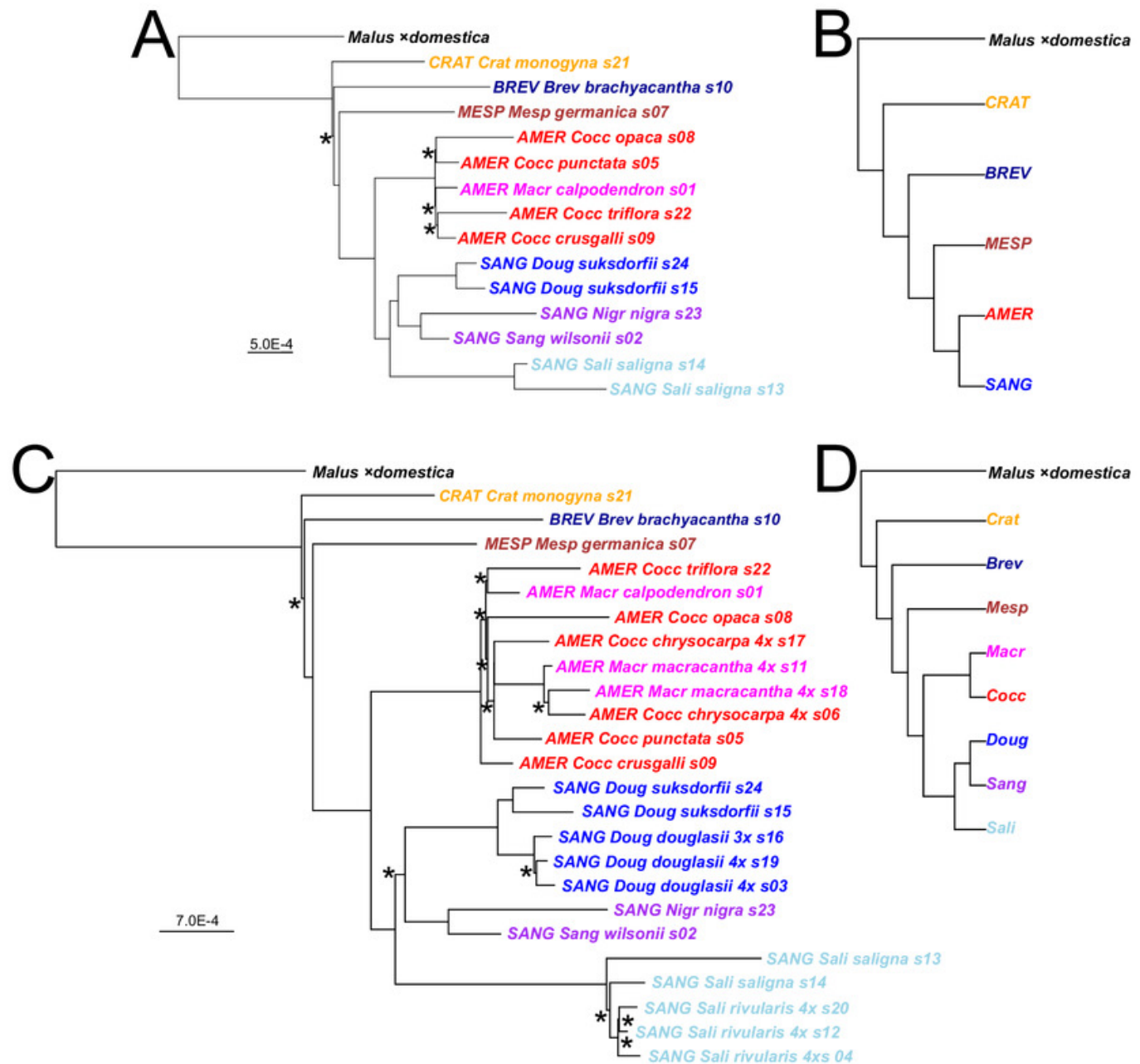


\section{Figure 3}

Impact on tree topology of including allotetraploids in a multilocus coalescent phylogeny of diploid Crataegus accessions.

(A) ASTRAL-III tree for 14 diploid Crataegus accessions (numbered as in Table 1) based on sequence data for 245 low copy number nuclear loci; (B) the tree in (A) collapsed by subgenera using the function makeCollapsedTree in the R package treespace (Jombart et al. 2017); (C) ASTRAL-III tree for the same 14 diploids plus 10 related allotetraploid Crataegus accessions (Table 1) based on sequence data for 244 low copy number nuclear loci; (D) the tree in (C) collapsed by subgenera using the $R$ function makeCollapsedTree. In (A) and (C) trees rooted using the corresponding sequences from the genome of apple, Malus $x$ domestica (Velasco et al. 2010). Accessions are coded as in earlier figures by Crataegus subgenera (MESP, BREV, CRAT, AMER, SANG) and sections (color; Mesp, Brev, Crat, Cocc, Macr, Doug, Sali, and series Sanguineae and Nigrae in section Sanguineae; Table 1). In (A) and $(C)$ nodes have local posterior probability support $\geq 0.95$ unless indicated otherwise $(*)$; scale bar for branch lengths in coalescent units (Sayyari \& Mirarab 2016). 


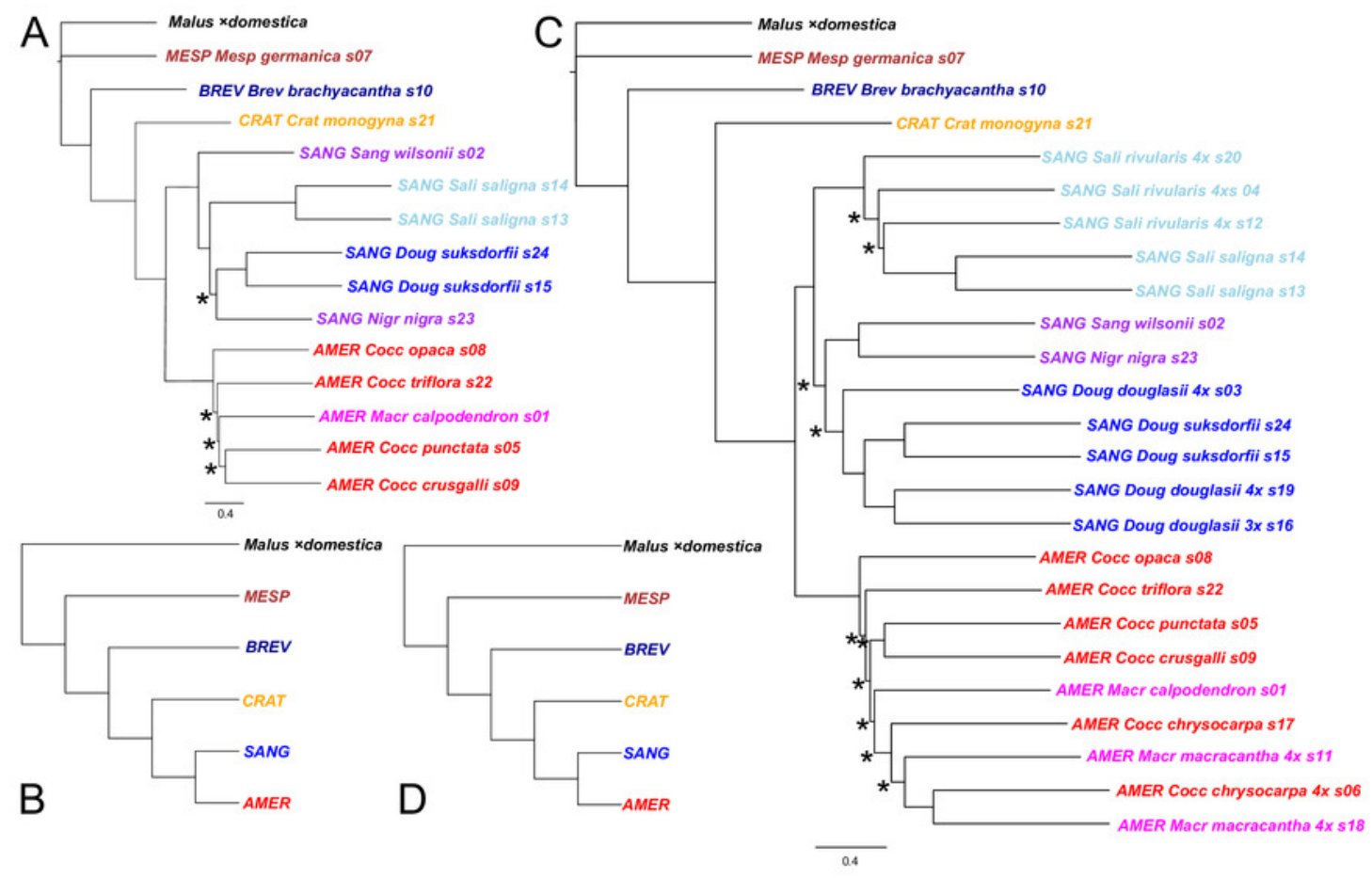




\section{Figure 4}

Impact on tree topologies of including allotetraploids on Principal Coordinates Analyses (PCoAs) of distances between plastome and 245 nuclear single-locus trees for diploid Crataegus accessions.

(A, C, E) PCoA of 246 trees calculated for the diploid accessions only (plastome tree +245 gene trees). (B, D, F) PCoA of 245 trees calculated for the diploid and tetraploid accessions (plastome tree +244 gene trees). (A, B) PCoA calculated from a matrix of related tree (RT) distances between the trees. (C, D) PCoA calculated from a matrix of multivariate (MV) distances between the trees. (E, F) PCoA calculated from a matrix of subtree membership divergence (SMD) distances between the trees. In each figure the position of the plastome tree is indicated by a plus sign (arrowed). Symbol color reflects the concordance between a gene tree and the corresponding plastome tree, collapsed with respect to the sectional affiliation of the accessions: red, trees within the fourth quartile of the concordances that are outliers; blue, trees in the first quartile of the concordances; all other trees gray. Note that the outgroup, apple, was used to root all trees in order to ensure topological consistency and facilitate visual comparison (Supplementary Fig. S1). The relative magnitudes of the eigenvalues in (A-F) are depicted in scree plots (Supplemental Fig. S4). 

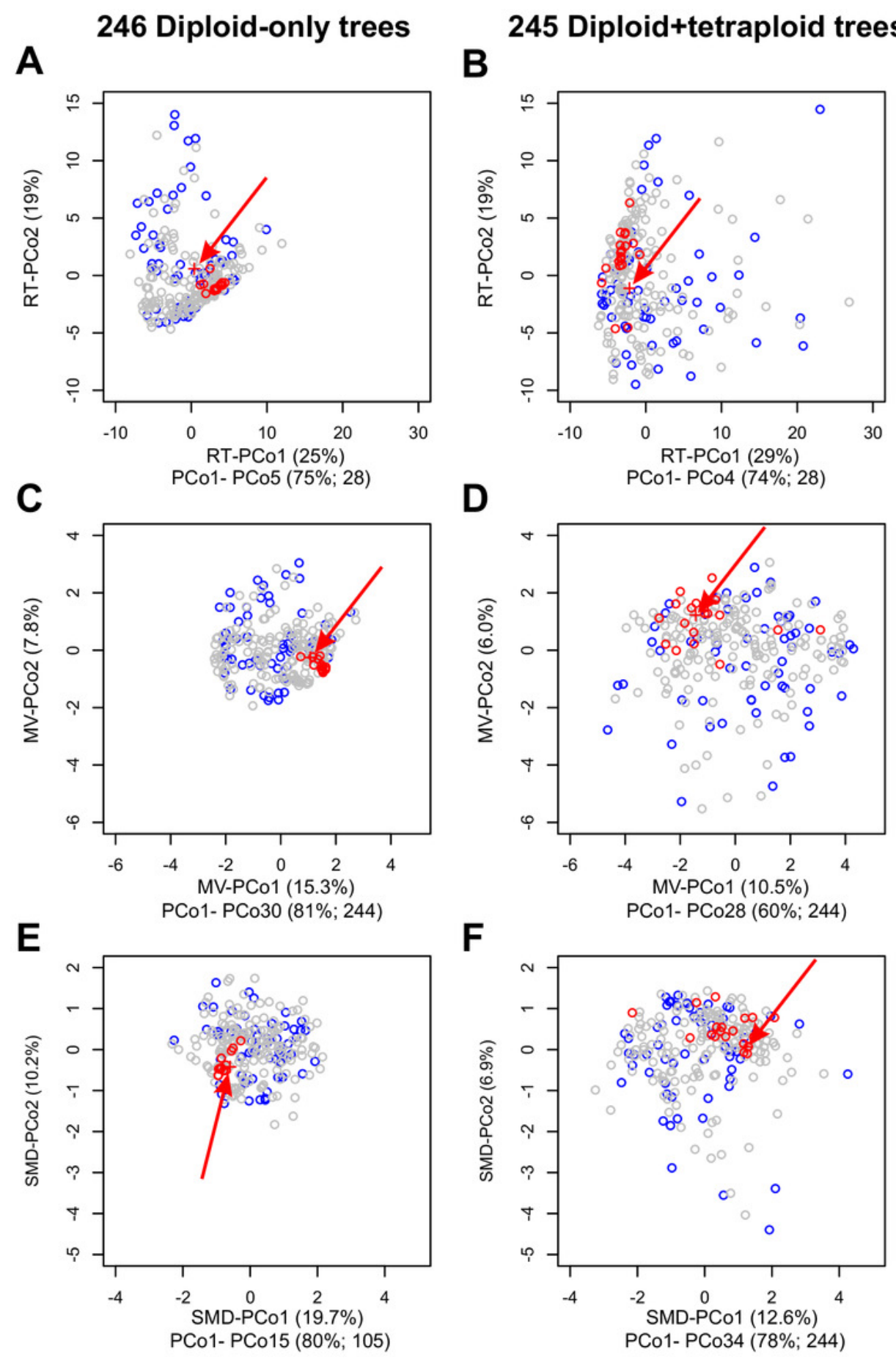


\section{Figure 5}

Impact on gene and site concordances of including allotetraploids in the multilocus ML phylogeny of diploid Crataegus accessions.

(A) Comparison of gene tree (gCF) and site (sCF) concordance values (Minh et al. 2020; Nguyen et al. 2015) for nodes shared between the IQ-TREE concatenated sequence trees for 14 diploid Crataegus accessions (B; Table 1 ) and for the same 14 diploids plus 10 related allotetraploid Crataegus accessions (C; Table 1). Red labels in (A) represent the nodes in (B); black labels in (A) represent the nodes in (C). Unless indicated otherwise (italicized proportions), nodes in (B) have bootstrap support $=1.00$ or $(C) \geq 0.98$. Scale bars for branch lengths are in substitution units. Pie charts show gene (gCF, red) and site (sCF, yellow) concordance values for nodes, as percentages. Green rectangles denote nodes at which the gene discordances $\left(\mathrm{gDF}_{1}, \mathrm{gDF}_{2}\right)$ both exceed $5 \%$. Orange rectangles denote nodes at which the chi-squared test rejects incomplete lineage sorting as the underlying cause of discordance among gene trees and sites (Lanfear 2018). Compare Supplemental Table S2. Accessions are coded as in earlier figures by Crataegus subgenera (MESP, BREV, CRAT, AMER, SANG) and sections (color; Mesp, Brev, Crat, Cocc, Macr, Doug, Sali, and series Sanguineae and Nigrae in section Sanguineae; Table 1). All trees rooted using the corresponding sequences from the genome of apple, Malus $\times$ domestica (Velasco et al. 2010). 


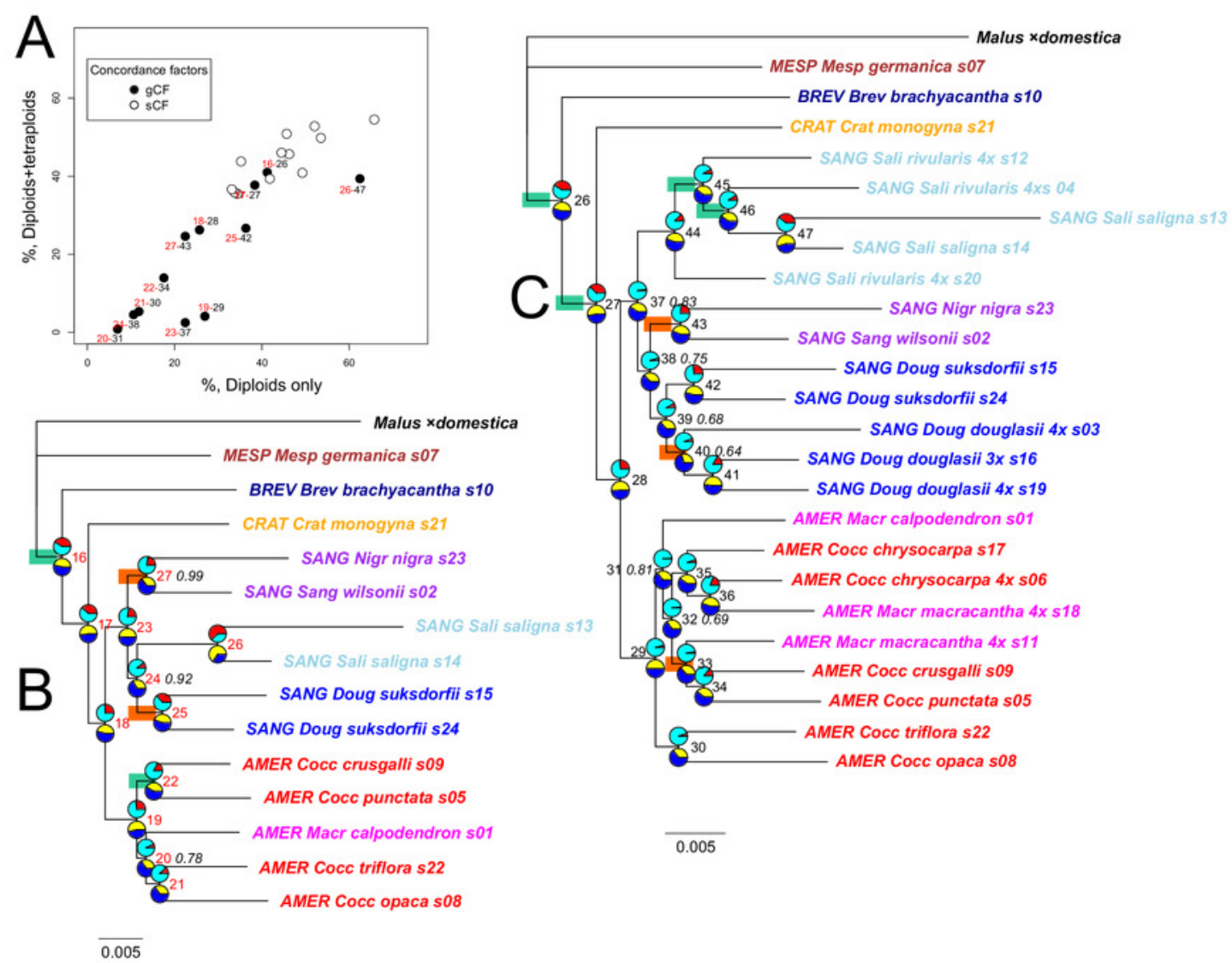




\section{Table $\mathbf{1}$ (on next page)}

Hawthorn individuals used here as sources of leaf tissue for DNA extraction, and for which ploidy level determined previously by flow cytometry (publications cited).

Classification follows Lo et al. (Lo et al. 2007; C. germanica), Ufimov (2013; C. subg. Sanguineae), Phipps (2015), and Ufimov \& Dickinson (2020). Voucher specimens are deposited in the Green Plant Herbarium of the Royal Ontario Museum (TRT). TRT accession numbers are linked to online specimen images; Target capture sequence data will be deposited in the National Center for Biotechnology Information Sequence Read Archive (NCBI SRA); TADCR numbers are searchable on the Barcode of Life Data System (BOLD; http://v4.boldsystems.org/ ). Sporophytic chromosome numbers (2n) are reported as multiples of the base number, $x=17$, based on flow cytometric determinations. Stamen numbers per flower $\left(A_{\#}\right)$. Localities represented here are in the United States or Canada. One sample of $C$. chrysocarpa lacks a flow cytometric ploidy determination; it is presumed $4 x$ based on data from another indistinguishable individual in the same population. 


\section{Table 1:}

2 Hawthorn individuals used here as sources of leaf tissue for DNA extraction, and for which ploidy level determined previously by flow cytometry (publications cited).

Classification follows Lo et al. (Lo et al. 2007; C. germanica), Ufimov (2013; C. subg. Sanguineae), Phipps (2015), and Ufimov \& Dickinson (2020). Voucher specimens are deposited in the Green Plant Herbarium of the Royal Ontario Museum (TRT). TRT 6 accession numbers are linked to online specimen images; Target capture sequence data will be deposited in the National Center for Biotechnology Information Sequence Read Archive (NCBI SRA); TADCR numbers are searchable on the Barcode of Life Data

8 System (BOLD; http://v4.boldsystems.org/). Sporophytic chromosome numbers $(2 n)$ are reported as multiples of the base number, $x=$

9 17, based on flow cytometric determinations. Stamen numbers per flower $\left(\mathrm{A}_{\#}\right)$. Localities represented here are in the United States or 10 Canada. One sample of C. chrysocarpa lacks a flow cytometric ploidy determination; it is presumed $4 x$ based on data from another 11 indistinguishable individual in the same population.

Crataegus L.

\begin{tabular}{|c|c|c|c|c|c|c|}
\hline $\begin{array}{l}\text { TRT Accession, NCBI } \\
\text { SRA, BOLD, and } \\
\text { sample numbers (this } \\
\text { study) }\end{array}$ & $\begin{array}{l}2 n ; \\
\mathrm{A}_{\#}\end{array}$ & $\begin{array}{l}\text { Collector \& } \\
\text { number }\end{array}$ & Publication & ;State level & County level & $\begin{array}{l}\text { Locality; Latitude, } \\
\text { Longitude } \\
\text { (degrees) for non- } \\
\text { botanical garden } \\
\text { specimens }\end{array}$ \\
\hline
\end{tabular}

\footnotetext{
subg. Mespilus Ufimov \& T. A. Dickinson

sect. Mespilus T. A. Dickinson \& E. Y. Y. Lo

C. germanica (L.) Kuntze
}

subg. Brevispinae (Beadle) Ufimov \& T. A. Dickinson

sect. Brevispinae Beadle ex Schneider

C. brachyacantha Sarg. \& Engelm.

$$
\frac{\text { TRT00000028; }}{\text { SAMN16630160; }}
$$

TRT00026642;
SAMN16630157;

$2 x$ $\mathrm{A}_{3}$

s.n.

Dickinsor.

Reid, C. 5203

$\mathrm{A}_{20}$

subg. Crataegus

sect. Crataegus

ser. Crataegus

C. monogyna Jacq.$$
\begin{array}{lllll}
\text { TRT00000394; } & 2 x & \text { Dickinson, T.A. } & \text { Zarrei et al., } 2015 & \text { Ontario } \\
\hline \text { SAMN16630171; } & \mathrm{A}_{20} & 2003-79
\end{array}
$$

Talent \& Dickinson, Louisiana 2005; Zarrei et al. 2015

(a)
Cultivated; U. of

California Botanic

Garden (78.0184)

ca. 3.75 miles NE of Oak Ridge; 32.66, -91.73 
subg. Americanae El-Gazzar sect. Coccineae Loudon

ser. Aestivales (Sarg.) Rehder

C. opaca Hook. \& Arn.

ser. Crus-galli (Loud.) Rehder

C. crus-galli $\mathrm{L}$.

SAMN16630158;

$2 x \quad$ Dickinson, T.A.

2003-33

Talent \& Dickinson

Louisiana

De Soto Parish

Cultivated; Trey

ewis home

place, 31.84

2015

$2 x \quad$ Talent, $\mathrm{N}$

Published here with Georgia

permission of $\mathrm{N}$.

Talent

ser. Punctatae (Loud.) Rehder

C. punctata Jacq.

TRT00002247;

SAMN16630155;

$2 x$

Purich, M.A. 81

Zarrei et al., 2015

Ontario

Durham R.M.

South of Big Indian Creek, road verge; 32.41 , $-83.57$

ser. Rotundifoliae (Egglest. ex Egglest.) Rehder

C. chrysocarpa Ashe
C. chrysocarpa Ashe
SAMN16630156; s06

$4 x$

Lo, E.Y.Y.

Talent \& Dickinson,

2005

See TRT barco

TRT00020434;

Coughlan, J.

link

ser. Triflorae (Beadle) Rehder

C. triflora Chapm.

TRT00021429;

SAMN16630172;

TADCR107; s22

Dickinson, T.A.

Talent \& Dickinson 2005; Zarrei et al.

2015

Idaho

Washington

Bowmanville,

between two forks

of Bowmanville

Creek; 43.90,

$-78.68$

Nez Perce Co. Hwy 3, at Little Potlatch Creek; 46.52, -116.73

N side of Palmer

Lake; 48.92 -

119.64

Autauga Co

Jones Bluff, SSW of Peace; 32.40 ,

$-86.78$

sect. Macracanthae Loudon

ser. Macracanthae (Loud.) Rehder

C. calpodendron (Ehrh.) Medikus

C. macracantha Lodd. ex Loud. var. occidentalis (Britt.) Egglest.

C. macracantha Lodd. ex Loud. var. occidentalis (Britt.) Egglest.
TRT00000105; SAMN16630151; s0

TRT00000142;

SAMN16630161; s11

$2 x$

Dickinson, T

2002-07A

Tale

Published here with

permission of $\mathrm{N}$.

Talent

TRT00020260;

SAMN16630168;

TADCR280; s18
Zarrei et al., 2015

$4 x \quad$ Coughlan, J.

JC168 
subg. Sanguineae Ufimov

sect. Salignae T.A. Dickinson \& Ufimov

ser. Cerrones J.B. Phipps

TRT00000946;

SAMN16630154;

Talent \& Dickinson,

Idaho

C. rivularis Nutt. ex Torr. \& A.Gray

TRT00000965;

TADCR165; s12

$4 x$

.

$$
015
$$

TRT00000976;

Dickinso

Zarrei et al., 2015

Nevada$$
2007-02
$$

Publish

C. rivularis Nutt. ex Torr. \& A.Gray

SAMN16630170; s20

$4 x \quad$ Talent, $\mathrm{N}$.

NT357

Published here with

permission of $\mathrm{N}$.

Talent

C. saligna Greene

TRT00001025;

Dickinson, T.A.

Dickin

SAMN16630163; s

2001-07

2008

C. saligna Greene

$\frac{\text { TRT00001047; }}{\text { SAMN16630164; }}$
TADCR120; s14

$2 x$

Dickinson, T.A.

2004-05

Talent \& Dickinson,

2005; Zarrei et al.,

2015

sect. Douglasianae (Rehder) C.K. Schneid.

ser. Douglasianae (Loud.) Poletiko

C. douglasii Lindl.
C. douglasii Lindl.
C. douglasii Lindl.
C. suksdorfii (Sarg.) Kruschke
C. suksdorfii (Sarg.) Kruschke

TRT00001145; $\underline{\text { SAMN16630153; }}$

TADCR001; s03

TRT00001279;

SAMN16630169;

TADCR177; s19

$4 x$

Lo, E. EL-1

Zarrei et al., 2015

Ontario

Lo, E. EL-170

Zarrei et al., 2015

Idaho

TRT00020479;

Coughlan, J.

SAMN16630166; s16

$\mathrm{A}_{10}$

JC224

See

TRT00020315;

SAMN16630174; s24

$2 x$

Coughlan, J.

JC033

TRT00001805;

$2 x \quad$ Zika, P.F.

18485
Grey Co.

Bear Lake Co. $\quad$ US 89 W of

Whitman Hollow;

$42.34,-111.21$

Elko Co. Starr Valley, on N side of Dennis Flats Road; 41.01, $-115.27$

Rio Arriba Co. US84, S end of

Chama; 36.87,

$-106.58$

Rio Blanco Co. Rio Blanco Rd 8,

$\mathrm{N}$ bank of White

River; 40.03 ,

$-107.86$

Duchesne Co. River Road, 4

miles $\mathrm{N}$ of

Duchesne; 40.21,

$-110.41$

Keppel Twp.,

Colpoy's Range;

44.80, 81.00

W bank of Goose

Creek, S of Last

Chance

Campground;

$44.99,-116.19$

Hwy 203, SE of

Union; 45.13

$-117.71$

Fay Lane, just W

of Scott R.; 41.40,

$-122.84$

ca. 1.5 air miles

NNW of

Ridgefield; 45.83,

$-122.75$ 
sect. Sanguineae Zabel ex C.K. Schneid.

ser. Nigrae (Loudon) Russanov

C. nigra Waldst. and Kit.

TRT00001999;

TADCR025; s23

$\begin{array}{ll}2 x & \text { Dickinson, T.A. } \\ \mathrm{A}_{20} & 2318-50\end{array}$

Talent \& Dickinson,

2005; Zarrei et al.,

Québec

2015

Cultivated; Jardin

Botanique de

Montréal,

Arboretum (2318-

ser. Sanguineae (Zabel ex C.K. Schneid.) Rehder

C. wilsonii Sarg.

TRT00002055;

SAMN16630152;

$2 x \quad$ Dickinson, T.A. Talent \& Dickinson,

Massachusetts

50)

TADCR114-10; s02

s.n.

2005; Zarrei et al.,

Cultivated;

Arnold Arboretum

(AA749-74A) 


\section{Table 2 (on next page)}

Intermediacy of allotetraploid Crataegus douglasii Lindl. and C. rivularis Nutt. with respect to their diploid progenitors in $C$. subg. Sanguineae Ufimov and sympatric tetraploid members of $C$. subg. Americanae El-Gazzar.

Ploidy level data as in Talent and Dickinson (2005) and Zarrei et al. (2015). Morphological and ecological data summarized from T. A. Dickinson, unpubl. mss; descriptors as in Dickinson et al. (2008). Geographic distribution (Canada, United States) as per Phipps (2015). 
1 Table 2:

2 Intermediacy of allotetraploid Crataegus douglasii Lindl. and $C$. rivularis Nutt. with respect 3 to their diploid progenitors in $C$. subg. Sanguineae Ufimov and sympatric tetraploid 4 members of $C$. subg. Americanae El-Gazzar.

Ploidy level data as in Talent and Dickinson (2005) and Zarrei et al. (2015). Morphological and ecological data summarized from T. A. Dickinson, unpubl. mss; descriptors as in Dickinson et al. (2008). Geographic distribution (Canada, United States) as per Phipps (2015).

\begin{tabular}{|c|c|c|c|}
\hline \multicolumn{4}{|c|}{ Allotetraploid Crataegus douglasii } \\
\hline & $\begin{array}{l}\text { C. subg. Sanguineae } \\
\text { C. suksdorfii }(2 x)\end{array}$ & allotetraploid & $\begin{array}{l}\text { C. } \text { subg. Americanae (4x) } \\
\text { (C. chrysocarpa s.l., } \\
\text { C. macracantha s.l.) }\end{array}$ \\
\hline Thorn length & Short & Intermediate & Long \\
\hline Leaf toothing & $5-7 / 1.0 \mathrm{~cm}$ & $8-10 / 1.0 \mathrm{~cm}$ & $7-12 / 1.0 \mathrm{~cm}$ \\
\hline Calyx lobe length & Short & Intermediate & Long \\
\hline $\begin{array}{l}\text { Calyx lobe } \\
\text { margination }\end{array}$ & Teeth absent & Intermediate & Teeth abundant \\
\hline Stamens per flower & Ca. 20 & Ca. 10 & Ca. 10 \\
\hline Styles per flower & $(3-) 4-5(-6)$ & $3-4(-5)$ & $2-3(-5)$ \\
\hline Ecological amplitude & Narrow & Broad & Broad \\
\hline Geographic range & $\begin{array}{l}\text { Northern CA, western } \\
\text { OR, southwestern WA }\end{array}$ & $\begin{array}{l}\text { AB, BC, CA, ID, MT, ON, } \\
\text { OR, WA }\end{array}$ & Nearly transcontinental \\
\hline \multicolumn{4}{|c|}{ Allotetraploid Crataegus rivularis } \\
\hline & $\begin{array}{l}\text { C. subg. Sanguineae } \\
\text { C. saligna }(2 \mathrm{x})\end{array}$ & allotetraploid & $\begin{array}{l}\text { C. } \text { subg. Americanae (4x) } \\
\text { (C. chrysocarpa s.l., } \\
\text { C. macracantha } \text { s.l.) }\end{array}$ \\
\hline Thorn length & Short & Short & Long \\
\hline $\begin{array}{l}\text { Calyx lobe } \\
\text { pubescence }\end{array}$ & Absent & Sparse & Abundant \\
\hline $\begin{array}{l}\text { Calyx lobe } \\
\text { margination }\end{array}$ & Teeth few or absent & Intermediate & Teeth abundant \\
\hline Stamens per flower & Ca. 20 & Ca. 10 & Ca. 10 \\
\hline Styles per flower & $4-5$ & $3-4(-5)$ & $2-4(-5)$ \\
\hline Ecological amplitude & Narrow & Broad & Broad \\
\hline Geographic range & $\begin{array}{l}\text { Western CO, } \\
\text { northeastern UT }\end{array}$ & $\begin{array}{l}\text { AZ, CO, ID, NM, NV, UT, } \\
\text { WY }\end{array}$ & Nearly transcontinental \\
\hline
\end{tabular}




\section{Table 3 (on next page)}

Results of population- and individual-level hybridization detection analyses using HyDe (Blischak et al. 2018).

For each putative allotetraploid (Hybrid), Parent 1 and Parent2 are Crataegus subg.

Sanguineae and $C$. subg. Americanae, respectively. Results are shown for $C$. douglasii and $C$. rivularis at the population level, and then the individual level (Table 1 ), where $\hat{\gamma}$ is the admixture statistic, tested for $\mathrm{H} 0: \mathrm{\gamma}=0$ versus $\mathrm{H} 1: \mathrm{\gamma}>0$. 
1

2

3 Table 3:

4 Results of population- and individual-level hybridization detection analyses using HyDe

5 (Blischak et al. 2018).

6

7 For each putative allotetraploid (Hybrid), Parent 1 and Parent2 are Crataegus subg. Sanguineae

8 diploids $^{1,3}$ and $C$. subg. Americanae tetraploids ${ }^{2}$, respectively (Table 1). Outgroups were the apple, C. monogyna (s21), C. germanica (s07), and C. brachyacantha (s10) accessions (Table 1). Results are shown for $C$. douglasii and C. rivularis at the population level, and then the individual level (Table 1), where $\hat{\gamma}$ is the admixture statistic, tested for $\mathrm{H}_{0}: \gamma=0$ versus $\mathrm{H}_{1}: \gamma>0$.

Parent1 Hybrid Parent2 Z-score P-value $\hat{\gamma}$

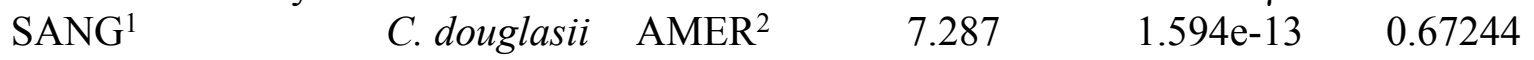

$\begin{array}{llllll}\text { SANG }^{1} & \text { s03dou } & \text { AMER }^{2} & 7.815 & 2.776 \mathrm{e}-15 & 0.60647\end{array}$

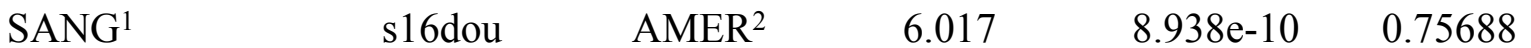

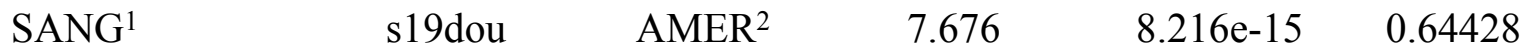

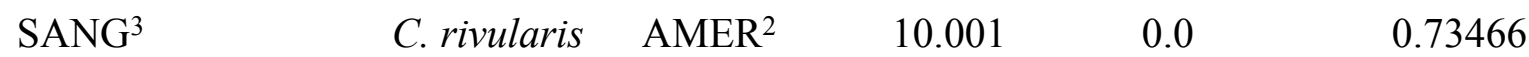

$\mathrm{SANG}^{3}$

s20riv

AMER $^{2} . \quad 10.011$

0.0

0.69301

$\mathrm{SANG}^{3}$

s04riv

AMER $^{2}$

9.751

0.0

0.77420

$\mathrm{SANG}^{3}$

s12riv

AMER $^{2}$

10.178

0.0

0.72819

${ }^{1}$ C. suksdorfii $\mathrm{s} 15, \mathrm{~s} 24$

${ }^{2}$ C. chrysocarpa $\mathrm{s} 06, \mathrm{~s} 17$, C. macracantha $\mathrm{s} 11, \mathrm{~s} 18$

${ }^{3}$ C. saligna $\mathrm{s} 13, \mathrm{~s} 14$ 